\title{
O IMPACTO DA INOVAÇÃO ORGANIZACIONAL NO DESEMPENHO PRODUTIVO E FINANCEIRO DE INDÚSTRIAS DE TRANSFORMAÇÃO SITUADAS NO BRASIL
}

Carlos Eduardo de Oliveira (Universidade Federal de Uberlândia - UFU)

Ana Paula Macedo de Avellar (Universidade Federal de Uberlândia - UFU)

\begin{abstract}
Resumo
O objetivo deste estudo foi verificar a realização da Inovação Organizacional (IO) nas indústrias situadas no Brasil, sua realização concomitantemente com outros tipos de inovação e analisar o impacto no desempenho das empresas, medido pela Receita Líquida de Vendas e pela Produtividade do Trabalho. Para verificar os efeitos da IO no desempenho (financeiro e produtivo) das indústrias de transformação presentes na edição de 2011 da Pesquisa de Inovação, utilizou-se estimação econométrica. Os principais resultados apontam que somente a $\mathrm{IO}$, ou a IO realizada concomitantemente com outros tipos de inovação, não apresentaram influência significativa no desempenho financeiro e produtivo.
\end{abstract}

Palavras-chave: Inovação; Inovação Organizacional; Análise de Desempenho; Setor Industrial.

\begin{abstract}
The aim of this study was to verify the achievement of Organizational Innovation (OI) in industries located in Brazil, its realization together with other types of innovation and analyze the impact on business performance, as measured by Net Sales Revenue and the Labour Productivity. To check the effects of IO performance (financial and productive) of the manufacturing industries present in the 2011 edition of the Innovation Survey, we used econometric estimation. The main results show that only IO, or IO held concurrently with other types of innovation, no significant influence on financial and productive performance.
\end{abstract}

Keywords: Innovation; Organizational Innovation; Performance Analysis; Industrial Sector.

Área 5: Inovação, competências e competitividade

JEL: O30 


\section{Introdução}

A implementação de inovações (produto, processo, organizacional e marketing) podem contribuir para o desempenho financeiro e produtivo das empresas. O objetivo deste estudo é identificar os efeitos da Inovação Organizacional (IO) no desempenho financeiro (medido pela Receita Líquida de Vendas RLV) e no desempenho produtivo (medido pela Produtividade do Trabalho - PT); e se a IO em conjunto com a Inovação Tecnológica (IT), afeta ainda mais esse desempenho, considerando-se, como hipótese, que a IO pode proporcionar impacto positivo no desempenho (financeiro e produtivo) das indústrias de transformação situadas no Brasil.

Foram considerados dez grupos de empresas, conforme o tipo de inovação realizada (somente produto, processo, IO ou marketing), e a realização de mais de um tipo de inovação concomitantemente (produto e processo - IT; produto e IO; processo e IO; marketing e IO; produto, processo e IO). Os dados utilizados foram obtidos da PINTEC de 2011, mediante acesso autorizado à sala de acesso a dados restritos do IBGE. A análise econométrica foi realizada utilizando-se do software STATA 12, e foram utilizadas como variáveis independentes: Pessoal Ocupado, Capital Estrangeiro, Grupo, Cooperação, Exportação, Apoio do Governo, P\&D contínuo, Gastos com Atividades Inovativas, Qualidade da Mão de Obra, Setor (CNAE 2.0) e Região Geográfica.

Para verificar os impactos da IO no desempenho (RLV e PT), foi realizada análise de regressão múltipla, com estimação dos parâmetros pelo método de Mínimos Quadrados Ordinários (MQO) e realizados testes de erro de especificação (Ramsey), multicolinearidade (VIF), heterocedasticidade (Breusch-Pagan, Cook-Weisberg) e de influência das variáveis no modelo (outliers).

Este estudo está estruturado em oito seções. A primeira seção apresenta esta introdução. A segunda seção realiza uma revisão teórica acerca da IO e o desempenho das empresas. Na terceira seção são apresentadas as notas metodológicas. A quarta seção apresenta as características das empresas inovadoras e os diferentes impactos analisados pela PINTEC. A quinta seção apresenta a análise dos resultados da estatística descritiva. A sexta seção apresenta os resultados dos estudos econométricos e, por fim, a sétima seção apresenta as considerações finais.

\section{Inovação Organizacional e Desempenho: revisão teórica}

O objetivo desta seção é apresentar uma revisão analítica da IO e o desempenho das firmas e, para isso, foi realizada extensa revisão da literatura, não com a intenção de esgotar a discussão, mas com o intuito de clarificar o atual debate acerca da relação da IO e o desempenho das empresas.

A contribuição independente da IO para o desempenho superior e para a competitividade de uma empresa vinha sendo largamente negligenciada, mas estudos realizados no final dos anos 1980 viraram a atenção de pesquisadores e gestores para a IO, considerando-a um fator determinante para a competitividade das empresas (WOMARK et al., 1990). Estudos recentes da literatura sobre inovação sugerem que a Inovação Organizacional desempenha um papel fundamental no desempenho organizacional de uma empresa competitiva (UZKURT, KUMAR e ENSARI, 2013).

Devido ao rápido avanço do conhecimento científico e técnico, e o crescente nível de concorrência em muitos setores, a IO torna-se uma das atividades estratégicas mais importantes para as empresas e, portanto, um dos temas mais amplamente investigados na teoria organizacional (KESSLER, 2004). No planejamento da estratégia a ser utilizada por uma empresa, os gestores devem levar em consideração, entre outros aspectos, a estrutura organizacional que ela possui atualmente, e a que pretende possuir no futuro.

Os trabalhos de microeconomistas no campo da estratégia consideram a estrutura organizacional como a causa e o efeito da escolha estratégica de gestão, em resposta às oportunidades de mercado (LAM, 2005). Considera-se, então, que a estrutura organizacional deve ser competente o suficiente para enfrentar as mudanças estratégicas, levando em conta as alterações tecnológicas que podem ocorrer dentro e fora da empresa. Considerando a importância da estrutura organizacional no processo de inovação, alguns aspectos sobre esse assunto são apresentados no Quadro 1. 
Quadro 1: Aspectos da relação entre IO e desempenho

\begin{tabular}{|c|c|}
\hline Autor & $\begin{array}{c}\text { Aspectos relevantes identificados } \\
\end{array}$ \\
\hline Ambruster et al. (2008) & $\begin{array}{l}\text { Uma IO torna-se eficaz em termos de influenciar positivamente os indicadores de } \\
\text { desempenho. }\end{array}$ \\
\hline $\begin{array}{l}\text { Caroli e Van Reenen (2001); } \\
\text { Damanpour et al. (1989); } \\
\text { Greenan (2003); Piva e } \\
\text { Vivarelli (2002) }\end{array}$ & $\begin{array}{l}\text { A adoção de conceitos organizacionais concretos tem um impacto fundamental sobre a } \\
\text { capacidade de uma empresa para melhorar o seu desempenho (AMBRUSTER et al., } \\
\text { 2008). }\end{array}$ \\
\hline Sapprasert e Clausen (2012) & $\begin{array}{l}\text { O estudo realizado descobriu que as firmas que combinaram IT com IO e de marketing } \\
\text { tiveram melhor desempenho em termos de vendas e redução de custos, e que a } \\
\text { combinação de inovação de produtos com IO teve um efeito significativo e positivo sobre } \\
\text { a lucratividade da empresa. }\end{array}$ \\
\hline Sapprasert e Clausen (2012) & $\begin{array}{l}\text { O efeito combinado de realizar a IO e IT no desempenho da empresa é positivo e } \\
\text { significativo. Portanto, as empresas podem colher os melhores frutos de uma } \\
\text { reorganização através da reorganização em conjunto da IT e IO. }\end{array}$ \\
\hline Pallas et al. (2013) & $\begin{array}{l}\text { Existe relação positiva entre a capacidade de inovação de uma empresa e seu } \\
\text { desempenho. A capacidade de inovação de uma empresa é um importante pré-requisito } \\
\text { para manter-se competitiva. }\end{array}$ \\
\hline Mol e Birkinshaw (2009) & ente associada ao desempenho da $\epsilon$ \\
\hline Evangelista e Vezzani (2010) & $\begin{array}{l}\text { Resultados de análise empírica revelam o importante papel desempenhado por mudanças } \\
\text { organizacionais (também quando estes não estão ligados a outros tipos de inovação) } \\
\text { como condutora de performance das empresas. }\end{array}$ \\
\hline Gunday et al. (2011) & $\begin{array}{l}\text { incipais motores do desempenho da empresa, e deve } \\
\text { arte integrante da estratégia de negócios. }\end{array}$ \\
\hline Camisón e Villar-López (2014) & $\begin{array}{l}\text { ento da capacidade de IT, e que, tanto a IO e a capacidade } \\
\text { cessos podem levar a um desempenho superior da firma. }\end{array}$ \\
\hline
\end{tabular}

Fonte: Elaboração própria.

Os gestores, no desenvolvimento da estratégia para a empresa, devem levar em consideração, entre outros aspectos, as condições estruturais da empresa, que tornam-se a base para que os planos possam ser desenvolvidos e executados. Essa estrutura organizacional deve estar preparada para proporcionar os resultados do planejamento estratégico, com vistas ao atingimento das metas estabelecidas. A IO também é fruto dos esforços individuais e coletivos dos funcionários, no sentido de se criar uma alternativa significativa ao que já existe, baseado ou não em uma IT. Os gestores devem reconhecer e gerenciar as inovações, a fim de aumentar o seu desempenho operacional; ter uma compreensão clara da natureza exata das inovações vai ajudar as empresas a priorizar suas estratégias de mercado, de produção e de tecnologia, a ser definido por um plano de ação apropriado (GUNDAY et al., 2011). Considera-se então, que as empresas devem levar em conta, no desenvolvimento de sua estratégia, as mudanças no ambiente, de forma que sua estrutura organizacional possa absorver tais mudanças, e sustentar a gestão no processo decisório.

As mudanças que ocorrem nas empresas não acontecem na mesma velocidade e de forma igual. Cada empresa reage à sua maneira, considerando mudanças ambientais. As organizações respondem de forma lenta e gradual às mudanças ambientais; organizações interligadas evoluem através de longos períodos de mudança incremental, e veem a evolução organizacional como intimamente ligada ao padrão cíclico da mudança tecnológica; as organizações nem sempre são beneficiárias passivas de forças ambientais, mas também têm o poder de influenciar e moldar o ambiente (LAM, 2005).

O estudo realizado por Gomes e Kruglianskas (2009), confirma a existência de uma associação entre o uso de práticas para a gestão de fontes externas de informação tecnológica, e o desempenho inovador das empresas analisadas. O estudo também identificou uma tendência de aumento do uso de fontes externas de informação tecnológica, e da existência de um grande espaço para melhorias das práticas gerenciais atuais adotadas pelas empresas.

Os resultados empíricos da pesquisa de Gallego, Rubalcaba e Hipp (2012) demonstram que a IO é altamente significativa para o desempenho de pequenas empresas envolvidas em IT, e que elas tendem a complementar as suas atividades internas de P\&D com a informação externa. A contribuição da IO, para o desenvolvimento técnico de pequenas empresas, pode ser um sinal da influência dos novos arranjos 
organizacionais no apoio à adoção, emprego e gestão de conhecimento externo (GALLEGO, RUBALCABA e HIPP, 2012). O Quadro 2 apresenta os resultados de alguns estudos internacionais acerca dos efeitos dos tipos de IO no desempenho das empresas.

Quadro 2: Estudos que examinam os efeitos dos tipos de inovação sobre o desempenho da empresa

\begin{tabular}{|c|c|c|}
\hline Estudo & Efeitos dos tipos de IO sobre o desempenho da empresa & Correlação \\
\hline $\begin{array}{l}\text { Jiménez-Jiménez \& } \\
\text { Sanz-Valle (2011) }\end{array}$ & $\begin{array}{l}\text { - IO tem uma relação positiva com o desempenho da empresa. } \\
\text { - A aprendizagem organizacional relaciona-se positivamente com o desempenho da empresa. } \\
\text { - A aprendizagem organizacional relaciona-se positivamente com a IO. }\end{array}$ & $\begin{array}{l}0.34 \text { a } 0.54 \\
0.38 \text { a } 0.41 \\
0.25 \text { a } 0.59\end{array}$ \\
\hline Calantone et al. (2002) & $\begin{array}{l}\text { - Quanto mais elevada a orientação de aprendizagem, maior será a capacidade de inovação } \\
\text { da empresa. } \\
\text { - Quanto mais elevada orientação de aprendizagem, maior será o desempenho da empresa. } \\
\text { - Quanto mais elevada a capacidade de inovação da empresa, maior será o desempenho da } \\
\text { empresa. }\end{array}$ & $\begin{array}{l}0.31 \text { a } 0.40 \\
0.18 \text { a } 0.45 \\
\quad 0.40\end{array}$ \\
\hline Gopalakrishnan (2000) & - Quanto maior a velocidade de adoção de inovações, maior será o desempenho financeiro. & 0.33 \\
\hline Damanpour et al. (2009) & $\begin{array}{l}\text { - Quanto maior a adoção cumulativa de tipos de inovação ao longo do tempo, melhor o } \\
\text { desempenho da organização. } \\
\text { - Consistência na adoção de uma composição similar de tipos de inovação ao longo do tempo } \\
\text { afeta positivamente o desempenho organizacional. }\end{array}$ & 0.13 \\
\hline Bowen et al. (2010) & - Inovação relaciona-se positivamente com o desempenho futuro. & 0.16 \\
\hline $\begin{array}{l}\text { Subramanian \& } \\
\text { Nilakanta (1996) }\end{array}$ & - Formalização pode ser associada com altos níveis de inovação administrativa. & 0.15 a 0.52 \\
\hline Sok \& O’ Cass (2011) & $\begin{array}{l}\text { - Inovação complementar está positivamente relacionada com o desempenho no domínio da } \\
\text { inovação. }\end{array}$ & 0.60 a 0.66 \\
\hline Baer \& Frese (2003) & $\begin{array}{l}\text { - Um ambiente de alto nível de iniciativas para a inovação de processos afetam as empresas } \\
\text { de forma positiva e seu desempenho. }\end{array}$ & 0.13 a 0.55 \\
\hline Wang et al. (2011) & - Existe uma relação positiva entre a confiança e as empresas de desempenho em inovação. & 0.49 \\
\hline Lin et al. (2013) & $\begin{array}{l}\text { - Desempenho da inovação de produto verde está associado positivamente com o } \\
\text { desempenho da empresa. }\end{array}$ & 0.75 \\
\hline $\begin{array}{l}\text { Aragon-Correa, } \\
\text { Garcia-Morales \& } \\
\text { Cordon-Pozo (2007) } \\
\end{array}$ & $\begin{array}{l}\text { - A aprendizagem organizacional influencia positivamente a inovação da empresa. } \\
\text { - A liderança transformacional influencia positivamente a inovação da empresa. } \\
\text { - Empresa inovadora poderá influenciar positivamente o desempenho. }\end{array}$ & $\begin{array}{l}0.59 \\
0.39 \\
0.51 \\
\end{array}$ \\
\hline $\begin{array}{l}\text { Camisón \& Villar- } \\
\text { López (2012) }\end{array}$ & $\begin{array}{l}\text { - O efeito da capacidade de inovação do processo no desempenho da empresa é mediada pelo } \\
\text { desenvolvimento de capacidades de inovação de produto. }\end{array}$ & 0.65 \\
\hline Huang \& Liu (2005) & $\begin{array}{l}\text { - A interação entre o capital de inovação e o capital da IT tem um efeito positivo sobre o } \\
\text { desempenho da empresa }\end{array}$ & 0.2 a 0.75 \\
\hline Ortt, van der Duin (2008) & - IO poderá ter um impacto positivo sobre o desempenho da empresa & 0.38 \\
\hline
\end{tabular}

Fonte: Adaptado de Hassan et al. (2013).

Os impactos que as inovações podem proporcionar no desempenho da empresa incluem, entre outros, incrementos sobre as vendas e sobre sua participação no mercado, bem como mudanças em sua eficiência e produtividade. São impactos importantes, no âmbito industrial e nacional, as mudanças na competitividade internacional e na produtividade total de fatores, os transbordamentos de conhecimento a partir de inovações na esfera da firma, e o aumento na quantidade de conhecimentos que circulam através das redes de comunicação. (OCDE, 2005).

Os resultados das correlações dos estudos apresentados no Quadro 2 sugerem relações positivas entre IO e o desempenho das empresas. Alguns aspectos específicos da IO apresentaram também relações positivas com o desempenho, como a aprendizagem, capacidade de inovação, velocidade de adoção de inovações, cumulatividade da inovação, formalização, inovação complementar (incremental), ambiente que propicie iniciativas para inovação e relações de confiança. Observou-se também que a maioria das correlações foram de fracas a moderadas, com destaque para a associação entre o desempenho da inovação de produto verde e o desempenho da empresa, por ser o item que apresentou o maior coeficiente associativo e estatisticamente significativo.

Considera-se relevante a apresentação dos principais estudos empíricos que apresentam resultados da IO no desempenho das empresas. Para isso, foram pesquisados artigos científicos que abordassem a discussão da relação da IO com o desempenho empresarial, procurando identificar as principais evidências dessa relação. Considerando a relevância dos estudos internacionais acerca da IO, o Quadro 3 resume os principais aspectos desses estudos, com a finalidade de compilar os resultados dos estudos acerca dos efeitos da IO no desempenho das empresas. 
Quadro 3: Síntese dos estudos apresentados acerca dos efeitos da IO no desempenho da empresa

\begin{tabular}{|c|c|c|c|c|c|c|}
\hline Ano & Autor & Objetivo & País & Base de Dados & $\begin{array}{c}\text { Método } \\
\text { Econométrico }\end{array}$ & Principais Resultados \\
\hline 2002 & $\begin{array}{c}\text { Totterdell et } \\
\text { al. }\end{array}$ & $\begin{array}{l}\text { Efeitos das inovações } \\
\text { nas finanças, } \\
\text { funcionários, clientes } \\
\text { e qualidade de vida }\end{array}$ & $\begin{array}{l}\text { Reino } \\
\text { Unido }\end{array}$ & $\begin{array}{l}\text { Entrevista } \\
\text { gerentes de } 513 \\
\text { empresas de cinco } \\
\text { setores industriais no } \\
\text { ano 2000 } \\
\end{array}$ & $\begin{array}{l}\text { Estatística descritiva; } \\
\text { análise discriminante }\end{array}$ & $\begin{array}{l}90 \% \text { das grandes inovações tem impacto } \\
\text { benéfico nas finanças, funcionários e clientes. }\end{array}$ \\
\hline 2007 & Guan e Liu & $\begin{array}{l}\text { Analisar a relação } \\
\text { entre IT e IO e a } \\
\text { competitividade } \\
\text { produto }\end{array}$ & China & $\begin{array}{l}\text { Dados do estudo de } \\
\text { empresas inovadoras } \\
\text { de Pequim, China }\end{array}$ & $\begin{array}{l}\text { SPSS; análise de } \\
\text { correlação canônica }\end{array}$ & $\begin{array}{l}\text { Relação positiva entre IT e IO; integração da } \\
\text { IT e IO é fundamental para melhorar a } \\
\text { competitividade de produto. }\end{array}$ \\
\hline 2009 & $\begin{array}{c}\text { Mol e } \\
\text { Birkinshaw }\end{array}$ & $\begin{array}{l}\text { Mostrar que a gestão } \\
\text { da inovação é uma } \\
\text { consequência do } \\
\text { contexto interno de } \\
\text { uma empresa e da } \\
\text { busca externa por } \\
\text { novos conhecimentos }\end{array}$ & $\begin{array}{l}\text { Reino } \\
\text { Unido }\end{array}$ & $\begin{array}{l}\text { Dados da CIS } 3 \text { de } \\
2001\end{array}$ & Logit, Tobit, OLS & $\begin{array}{l}\text { A gestão da inovação está positivamente } \\
\text { associada com o desempenho da empresa sob a } \\
\text { forma de crescimento da produtividade. }\end{array}$ \\
\hline 2010 & $\begin{array}{l}\text { Evangelista e } \\
\text { Vezzani }\end{array}$ & $\begin{array}{l}\text { IT e IO e o impacto } \\
\text { sobre o desempenho }\end{array}$ & Itália & $\begin{array}{l}\text { CIS4 referente ao } \\
\text { período de } 2002 \text { a } \\
2004\end{array}$ & Probit & $\begin{array}{l}\text { A combinação de IT e IO tem impacto superior } \\
\text { sobre o desempenho (crescimento econômico } \\
\text { do volume de negócios), comparado com a } \\
\text { realização isolada de um tipo de inovação. }\end{array}$ \\
\hline 2011 & $\begin{array}{l}\text { Salim e } \\
\text { Sulaiman }\end{array}$ & $\begin{array}{lll}\text { Efeito da } & \text { IO } & \text { no } \\
\text { desempenho } & & \text { da } \\
\text { empresa } & & \\
\end{array}$ & Malásia & $\begin{array}{l}\text { Dados de } 115 \text { PMEs } \\
\text { do setor de TIC }\end{array}$ & Estatística descritiva & $\begin{array}{l}\text { A IO tem influência significativa no } \\
\text { desempenho da empresa. }\end{array}$ \\
\hline 2011 & Gunday et al. & $\begin{array}{l}\text { Efeitos de inovações } \\
\text { de processo, produto, } \\
\text { organizacionais e de } \\
\text { marketing sobre o } \\
\text { desempenho da } \\
\text { empresa }\end{array}$ & Turquia & $\begin{array}{l}\text { Survey com } 311 \\
\text { questões aplicadas em } \\
184 \text { indústrias entre } \\
2006 \text { e } 2007 \text { ( } 7 \text { meses) }\end{array}$ & Estatística descritiva & $\begin{array}{l}\text { As IO têm um papel fundamental para a } \\
\text { capacidade de inovação, uma vez que tem o } \\
\text { maior coeficiente de regressão com o } \\
\text { desempenho inovador; as IO preparam um } \\
\text { ambiente adequado para os outros tipos de } \\
\text { inovação; as IO têm impacto forte e direto } \\
\text { sobre o desempenho inovador. }\end{array}$ \\
\hline 2012 & $\begin{array}{l}\text { Prester e } \\
\text { Bozac }\end{array}$ & $\begin{array}{l}\text { Práticas } \\
\text { organizacionais e o } \\
\text { impacto positivo para } \\
\text { a inovação }\end{array}$ & Croácia & $\begin{array}{l}\text { Dados da European } \\
\text { Manufacturing } \\
\text { Innovation Survey } \\
\text { (EMIS), em } 2009\end{array}$ & $\begin{array}{l}\text { Multi-regressão; } \\
\text { análise de correlação }\end{array}$ & $\begin{array}{l}\text { Práticas organizacionais inovadoras mais } \\
\text { utilizadas e identificadas aquelas que mais } \\
\text { influenciam a inovação. }\end{array}$ \\
\hline 2012 & $\begin{array}{l}\text { Sapprasert e } \\
\text { Clausen }\end{array}$ & $\begin{array}{l}\text { Relação da IO com a } \\
\text { IT e sua influência } \\
\text { sobre o desempenho }\end{array}$ & Noruega & $\begin{array}{l}\text { CIS } 3 \text { (1999-2001) e } \\
\text { CIS } 4 \text { (2002-2004) }\end{array}$ & $\begin{array}{l}\text { Estatística descritiva; } \\
\text { modelo de Heckman; } \\
\text { OLS }\end{array}$ & $\begin{array}{l}\text { A persistência na IO das empresas levou ao seu } \\
\text { desempenho positivo; a combinação de IO e IT } \\
\text { aumentam o desempenho positivo; as empresas } \\
\text { maiores e mais antigas são mais inclinadas a } \\
\text { tentar a mudança organizacional e as empresas } \\
\text { menores são as que mais se beneficiam. }\end{array}$ \\
\hline 2013 & Hassan et al. & $\begin{array}{l}\text { Explorar os efeitos de } \\
\text { tipos de inovação, } \\
\text { incluindo produto, } \\
\text { processo, marketing e } \\
\text { IO no desempenho da } \\
\text { empresa }\end{array}$ & Paquistão & $\begin{array}{l}\text { Survey; } 150 \text { empresas } \\
\text { listadas na Karachi } \\
\text { Stock Exchange (KSE) } \\
\text { foram entrevistadas }\end{array}$ & $\begin{array}{l}\text { Estatística descritiva; } \\
\text { correlação }\end{array}$ & $\begin{array}{l}\text { Efeitos positivos dos tipos de inovação sobre o } \\
\text { desempenho da empresa. }\end{array}$ \\
\hline 2013 & Laforet & $\begin{array}{l}\text { Impacto dos } \\
\text { resultados positivos e } \\
\text { negativos da IO nas } \\
\text { PMEs em relação ao } \\
\text { tamanho, idade e setor }\end{array}$ & $\begin{array}{l}\text { Reino } \\
\text { Unido }\end{array}$ & $\begin{array}{l}\text { Survey; } 96 \text { PMEs } \\
\text { pesquiadas }\end{array}$ & $\begin{array}{l}\text { Estatística descritiva; } \\
\text { escala Likert de cinco } \\
\text { pontos }\end{array}$ & $\begin{array}{l}\text { IO tem maior impacto sobre as empresas com } \\
0-49 \text { funcionários; melhora a margem de lucro } \\
\text { e a competitividade; grande impacto no setor } \\
\text { de engenharia; efeito negativo sobre as } \\
\text { empresas antigas. }\end{array}$ \\
\hline 2013 & Noruzy et al. & $\begin{array}{l}\text { Relações entre } \\
\text { aprendizagem, gestão } \\
\text { do conhecimento, IO e } \\
\text { desempenho } \\
\text { organizacional } \\
\end{array}$ & Irã & $\begin{array}{l}\text { Survey com duzentos e } \\
\text { oitenta gerentes de } \\
\text { nível sênior de } 106 \\
\text { empresas com mais de } \\
50 \text { empregados }\end{array}$ & $\begin{array}{l}\text { Modelagem de } \\
\text { equações estruturais }\end{array}$ & $\begin{array}{l}\text { Aprendizagem organizacional e gestão do } \\
\text { conhecimento são diretamente influenciadas } \\
\text { pela IO; a aprendizagem organizacional e a IO } \\
\text { influenciaram diretamente o desempenho } \\
\text { organizacional. }\end{array}$ \\
\hline 2014 & $\begin{array}{l}\text { Camisón e } \\
\text { Villar-López }\end{array}$ & $\begin{array}{l}\text { Avaliar a relação entre } \\
\text { IO e a IT }\end{array}$ & Espanha & $\begin{array}{l}\text { Survey da Sistema de } \\
\text { Análisis de Balances } \\
\text { Ibéricos (SABI) de } \\
144 \text { indústrias em } \\
2006 \\
\end{array}$ & $\begin{array}{l}\text { Correlação, mínimos } \\
\text { quadrados parciais } \\
\text { (PLS) }\end{array}$ & $\begin{array}{l}\text { A IO favorece o desenvolvimento de } \\
\text { capacidades de IT. A IO e a IT (produtos e } \\
\text { processos) pode levar a um desempenho } \\
\text { superior da firma. }\end{array}$ \\
\hline
\end{tabular}

Fonte: Elaborado pelo autor.

\section{Notas metodológicas}

A estratégia empírica deste estudo está organizada em duas etapas. Na primeira etapa da estratégia empírica é desenvolvida uma análise de estatística descritiva da amostra de empresas analisadas, e na segunda parte, realiza-se um estudo econométrico para testar a relação entre inovação organizacional e desempenho das empresas (RLV e PT).

A segunda etapa da estratégia empírica constitui a estimação de modelos econométricos. O desempenho das empresas será medido pelo desempenho financeiro (Receita Líquida de Vendas) e pelo desempenho produtivo (Produtividade do Trabalho). Para a análise do desempenho (financeiro e produtivo), foi efetuada a análise de regressão múltipla, para cada um dos grupos de empresas, por se 
tratar de conhecer os efeitos que algumas variáveis exercem ou podem exercer sobre as outras utilizadas em um estudo. A análise de regressão múltipla é um método muito usado em pesquisas empíricas por permitir controlar explicitamente outros fatores que, de maneira simultânea, afetam a variável dependente (WOOLDRIDGE, 2010).

Inicialmente, as empresas foram divididas em grupos, de acordo com o tipo de inovação realizada. Para cada grupo foram analisadas as variáveis consideradas no Quadro 4.

Quadro 4: Variáveis utilizadas no estudo

\begin{tabular}{|c|c|c|}
\hline \multicolumn{3}{|r|}{ CARACTERÍSTICAS GERAIS } \\
\hline Código & Variável & Descrição \\
\hline $\mathrm{PO}$ & Pessoal Ocupado & Número de Trabalhadores. Capta o tamanho da empresa. Número de pessoas ocupadas na empresa. \\
\hline $\mathrm{CE}$ & Capital Estrangeiro & $\begin{array}{l}\text { Variável Binária, que recebe valor unitário caso a origem do capital controlador da firma é estrangeiro ou } \\
\text { misto. }\end{array}$ \\
\hline GRU & Grupo & Variável Binária, que recebe valor unitário caso a firma faça parte de um grupo. \\
\hline COOP & Cooperação & $\begin{array}{l}\text { Variável Binária, que recebe valor unitário caso a firma esteve envolvida em arranjos cooperativos com } \\
\text { outra(s) organização (ões) com vistas a desenvolver atividades inovativas. }\end{array}$ \\
\hline EXP & Exportação & Variável Binária, que recebe valor unitário caso a firma tenha realizado exportações no período. \\
\hline APOIO & Apoio do Governo & $\begin{array}{l}\text { Varável Binária, que recebe valor unitário caso a firma utilize algum programa de apoio do governo para } \\
\text { as atividades inovativas. }\end{array}$ \\
\hline CONT & P\&D Contínuo & Varável Binária, que recebe valor unitário caso a empresa afirme realizar P\&D contínuo. \\
\hline GAI & $\begin{array}{l}\text { Gastos com Atividades } \\
\text { Inovativas }\end{array}$ & Logaritmo do Valor total dos gastos realizados em atividades inovativas. \\
\hline QMO & Qualidade da mão-de-obra & $\begin{array}{l}\text { Variável Binária, que recebe valor unitário caso a firma possua mão-de-obra com nível de qualificação } \\
\text { superior nas atividades internas de P\&D. }\end{array}$ \\
\hline \multicolumn{3}{|r|}{ SETOR DE ATIVIDADE ECONÔMICA } \\
\hline SET & Setor & $\begin{array}{l}\text { Conjunto de } 24 \text { Variáveis Binárias de atividades econômicas das indústrias de transformação, definidas à } \\
\text { partir de dois dígitos da CNAE 2.0. }\end{array}$ \\
\hline \multicolumn{3}{|r|}{ REGIÃO GEOGRÁFICA } \\
\hline RSUL & Região Sul & $\begin{array}{l}\text { Variável binária, que recebe o valor } 1 \text { se a empresa estiver localizada na Região Sul, ou seja, nas } \\
\text { Unidades da Federação: RS, SC e PR. }\end{array}$ \\
\hline RSUD & Região Sudeste & $\begin{array}{l}\text { Variável binária, que recebe o valor } 1 \text { se a empresa estiver localizada na Região Sudeste, ou seja, nas } \\
\text { Unidades da Federação: SP, RJ, MG, ES. }\end{array}$ \\
\hline RCO & Região Centro-Oeste & $\begin{array}{l}\text { Variável binária, que recebe o valor } 1 \text { se a empresa estiver localizada na Região Centro-Oeste, ou seja, } \\
\text { nas Unidades da Federação: GO, MS, MT, DF. }\end{array}$ \\
\hline RND & Região Nordeste & $\begin{array}{l}\text { Variável binária, que recebe o valor } 1 \text { se a empresa estiver localizada na Região Nordeste, ou seja, nas } \\
\text { Unidades da Federação: MA, PI, PE, CE, RN, BA, AL, SE, PB. }\end{array}$ \\
\hline RNT & Região Norte & $\begin{array}{l}\text { Variável binária, que recebe o valor } 1 \text { se a empresa estiver localizada na Região Norte, ou seja, nas } \\
\text { Unidades da Federação: AC, AP, AM, PA, RO, RR, TO. }\end{array}$ \\
\hline \multicolumn{3}{|r|}{ RECEITA LÍQUIDA DE VENDAS E PRODUTIVIDADE DO TRABALHO } \\
\hline RLV & Receita Líquida de Vendas & Valor da Receita Líquida de Vendas. \\
\hline PT & Produtividade do Trabalho & $\mathrm{VTI} / \mathrm{PO}$ \\
\hline
\end{tabular}

Fonte: Elaborado pelo autor.

Para estimar os parâmetros da análise de regressão múltipla, foi utilizado o método de Mínimos Quadrados Ordinários (MQO), que escolhe as estimativas que minimizam a soma dos quadrados dos resíduos, e realizado o teste de erro de especificação (Ramsey RESET). Foram aplicados testes de multicoliearidade (VIF), heterocedasticidade (Breusch-Pagan, Cook-Weisberg) e o teste sobre influências das variáveis do modelo (outliers).

As equações a seguir exemplificam as relações que foram investigadas. A primeira equação foi utilizada para verificar os tipos de inovação que proporcionaram impacto positivo no desempenho financeiro, medido pela RLV. A segunda equação foi utilizada para verificar os tipos de inovação que proporcionaram impacto positivo no desempenho produtivo, medido pela PT.

$\boldsymbol{R} \boldsymbol{L} \boldsymbol{V}=\alpha+\lambda_{1} \ln P$ essoalOcupado $+\lambda_{2}$ PessoalOcupado ${ }^{2}+\lambda_{3}$ CapitalEstrangeiro $+\lambda_{4}$ Grupo + $\lambda_{5}$ Cooperação $+\beta_{1}$ Exportação $+\beta_{2}$ ApoioGoverno $+\beta_{3} P \& D$ Contínuo $+\beta_{4}$ InGastos com Atividades Inovativas $+\beta_{5}$ Qualidade mão de obra $+\pi_{1}$ Setor $+\pi_{2}$ Região $+\boldsymbol{\mu}_{3}$ Inovação (1)

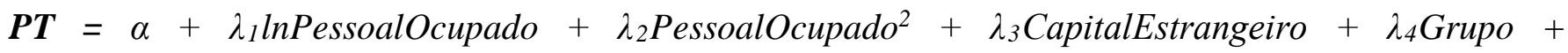
$\lambda_{5}$ Cooperação $+\beta_{1}$ Exportação $+\beta_{2}$ ApoioGoverno $+\beta_{3} P \& D$ Contínuo $+\beta_{4}$ InGastos com Atividades Inovativas $+\beta_{5}$ Qualidade mão de obra $+\pi_{1}$ Setor $+\pi_{2}$ Região $+\boldsymbol{\mu}_{3}$ Inovação (2)

As equações foram estimadas para cada um dos grupos de empresas inovadoras. Nesta fase da pesquisa, foi necessário o ingresso autorizado à sala de acesso a dados restritos do IBGE, e utilizado o software STATA versão 12. 


\section{Características das empresas inovadoras analisadas pela PINTEC}

Esta seção apresenta alguns resultados e características das empresas inovadoras. Uma análise importante pode ser realizada comparando-se a RLV por grupo de empresas selecionadas com os dispêndios realizados nas atividades inovativas, considerando os dados da Tabela 1.

Tabela 1: Receita Líquida de Vendas e o Total dos Gastos com atividades inovativas por grupo de empresas selecionadas - período 2006-2008 e 2009-2011

\begin{tabular}{|c|c|c|c|c|c|c|}
\hline \multirow{3}{*}{ Grupos de empresas selecionadas } & \multicolumn{3}{|c|}{ 2006-2008 } & \multicolumn{3}{|c|}{ 2009-2011 } \\
\hline & \multirow{2}{*}{$\begin{array}{c}\text { Receita } \\
\text { líquida } \\
\text { de vendas } \\
(1000 \mathrm{R} \$) \\
(1)\end{array}$} & \multicolumn{2}{|c|}{$\begin{array}{l}\text { Dispêndios realizados nas atividades } \\
\text { inovativas }\end{array}$} & \multirow{2}{*}{$\begin{array}{c}\text { Receita } \\
\text { líquida } \\
\text { de vendas } \\
(1000 \mathrm{R} \$) \\
(2)\end{array}$} & \multicolumn{2}{|c|}{$\begin{array}{l}\text { Dispêndios realizados nas atividades } \\
\text { inovativas }\end{array}$} \\
\hline & & $\begin{array}{c}\text { Valor } \\
(1000 \text { R } \$)\end{array}$ & $\%$ & & $\begin{array}{c}\text { Valor } \\
(1000 \mathrm{R} \$)\end{array}$ & $\%$ \\
\hline \multirow{2}{*}{ Inovadoras } & 1799588828 & 54103620 & $3,0 \%$ & 2447631087 & 64863726 & $2,7 \%$ \\
\hline & $100 \%$ & $100 \%$ & & $100 \%$ & $100 \%$ & \\
\hline \multirow{2}{*}{ Somente inovação de produto } & 12200004 & 360716 & $3,0 \%$ & 15665495 & 136585 & $0,9 \%$ \\
\hline & $0,7 \%$ & $0,7 \%$ & & $0,6 \%$ & $0,2 \%$ & \\
\hline \multirow{2}{*}{ Somente inovação de processo } & 21142333 & 1102725 & $5,2 \%$ & 26805378 & 1673489 & $6,2 \%$ \\
\hline & $1,2 \%$ & $2,0 \%$ & & $1,1 \%$ & $2,6 \%$ & \\
\hline \multirow{2}{*}{ Somente IO } & 120640499 & - & $0,0 \%$ & 282560543 & - & $0,0 \%$ \\
\hline & $6,7 \%$ & $0,0 \%$ & & $11,5 \%$ & $0,0 \%$ & \\
\hline \multirow{2}{*}{ Somente inovação em marketing } & 42847290 & - & $0,0 \%$ & 40994331 & - & $0,0 \%$ \\
\hline & $2,4 \%$ & $0,0 \%$ & & $1,7 \%$ & $0,0 \%$ & \\
\hline \multirow{2}{*}{ IT } & 1504183658 & 54103620 & $3,6 \%$ & 1927090291 & 64863726 & $3,4 \%$ \\
\hline & $83,6 \%$ & $100 \%$ & & $78,7 \%$ & $100 \%$ & \\
\hline IO e/ou marketing & 1732934510 & 51505516 & $3,0 \%$ & 2316986845 & 61640415 & $2,7 \%$ \\
\hline \multirow{2}{*}{ Inovação de produto e/ou IO } & 1724793730 & 52608719 & $3,1 \%$ & 2348441385 & 62722468 & $2,7 \%$ \\
\hline & $95,8 \%$ & $97,2 \%$ & & $95,9 \%$ & $96,7 \%$ & \\
\hline \multirow{2}{*}{ Inovação de processo e/ou IO } & 1732770127 & 53522368 & $3,1 \%$ & 2357879114 & 64544518 & $2,7 \%$ \\
\hline & $96,3 \%$ & $98,9 \%$ & & $96,3 \%$ & $99,5 \%$ & \\
\hline \multirow{2}{*}{ Inovação de produto, processo e/ou IO } & 1397965469 & 49549453 & $3,5 \%$ & 1746296698 & 57824931 & $3,3 \%$ \\
\hline & $77,7 \%$ & $91,6 \%$ & & $71,3 \%$ & $89,1 \%$ & \\
\hline \multicolumn{7}{|c|}{ Grupos selecionados por tipo de IO realizada } \\
\hline \multirow{3}{*}{ Inovação em Técnicas de Gestão } & 1427330422 & 44411378 & $3,1 \%$ & 1894991806 & 52834732 & $2,8 \%$ \\
\hline & $79,3 \%$ & $82,1 \%$ & & $77,4 \%$ & $81,5 \%$ & \\
\hline & 1150663845 & 35149544 & $3,1 \%$ & 1580318285 & 41014966 & $2,6 \%$ \\
\hline \multirow[t]{2}{*}{ Inovação em Técnicas de Gestão Ambiental } & $63,9 \%$ & $65,0 \%$ & & $64,6 \%$ & $63,2 \%$ & \\
\hline & 1064815716 & 35801754 & $3,4 \%$ & 1683984138 & 45785087 & $2,7 \%$ \\
\hline \multirow[t]{2}{*}{ Inovação em Métodos de Organização do Trabalho } & $59,2 \%$ & $66,2 \%$ & & $68,8 \%$ & $70,6 \%$ & \\
\hline & 744136181 & 23887909 & $3,2 \%$ & 1017633554 & 25911388 & $2,5 \%$ \\
\hline Inovação nas Relações com Outras Organizações & $41,4 \%$ & $44,2 \%$ & & $41,6 \%$ & $39,9 \%$ & \\
\hline
\end{tabular}

Fonte: IBGE, Diretoria de Pesquisas, Coordenação de Indústria, Pesquisa Industrial de Inovação 2008 e 2011. (1) Receita líquida de vendas de produtos e serviços, estimada a partir dos dados da amostra da Pesquisa Industrial Anual - Empresa 2008 e da Pesquisa Anual de Serviços 2008. (2) Receita líquida de vendas de produtos e serviços, estimada a partir dos dados da amostra da Pesquisa Industrial Anual - Empresa 2011 e da Pesquisa Anual de Serviços 2011.

Analisando-se a relação entre a RLV das empresas pertencentes aos grupos que realizaram mais de um tipo de inovação, foi possível observar a diminuição desta relação, o que indica a diminuição percentual dos dispêndios com inovação em relação à RLV. Apesar do aumento da RLV em todos os grupos de empresas que realizaram mais de um tipo de inovação, o aumento dos dispêndios não foi proporcional. A diminuição dessa relação também pode ser observada nos grupos de empresas selecionados por tipo de IO realizada. Na Tabela 2 será apresentada a Produtividade do Trabalho (PT) por grupo de empresas e por faixa de pessoal ocupado.

Tabela 2: Produtividade do Trabalho por grupo de empresas e por faixa de pessoal ocupado - período 2009-2011

\begin{tabular}{|c|c|c|c|c|c|c|c|}
\hline \multirow[b]{3}{*}{ Grupos de empresas selecionados } & \multicolumn{7}{|c|}{ Empresas } \\
\hline & \multicolumn{7}{|c|}{ Período 2009-2011 } \\
\hline & \multicolumn{7}{|c|}{ Produtividade do Trabalho (PT=VTL/PO) } \\
\hline \multirow{2}{*}{ Inovadoras } & 128,96 & 45,73 & $35,5 \%$ & 76,26 & $59,1 \%$ & 179,67 & $139,3 \%$ \\
\hline & $100,0 \%$ & $100,0 \%$ & & $100,0 \%$ & & $100,0 \%$ & \\
\hline Somente inovação de produto & 89,98 & 0 & $0 \%$ & 78,24 & $87,0 \%$ & 127,00 & $141,1 \%$ \\
\hline Somente inovação de processo & 56,58 & 35,10 & $62,0 \%$ & 58,13 & $102,7 \%$ & 88,66 & $156,7 \%$ \\
\hline
\end{tabular}




\begin{tabular}{|c|c|c|c|c|c|c|c|}
\hline & $43,9 \%$ & $76,8 \%$ & & $76,2 \%$ & & $49,3 \%$ & \\
\hline \multirow{2}{*}{ Somente IO } & 82,79 & 49,05 & $59,2 \%$ & 81,37 & $98,3 \%$ & 103,78 & $125,3 \%$ \\
\hline & $64,2 \%$ & $107,3 \%$ & & $106,7 \%$ & & $57,8 \%$ & \\
\hline \multirow{2}{*}{ Somente inovação em marketing } & 52,23 & 38,55 & $73,8 \%$ & 43,65 & $83,6 \%$ & 89,58 & $171,5 \%$ \\
\hline & $40,5 \%$ & $84,3 \%$ & & $57,2 \%$ & & $49,9 \%$ & \\
\hline \multirow{2}{*}{ IT } & 161,34 & 49,24 & $30,5 \%$ & 81,61 & $50,6 \%$ & 209,77 & $130,0 \%$ \\
\hline & $125,1 \%$ & $107,7 \%$ & & $107,0 \%$ & & $116,8 \%$ & \\
\hline \multirow{2}{*}{ IO e/ou marketing } & 129,64 & 46,69 & $36,0 \%$ & 75,33 & $58,1 \%$ & 179,40 & $138,4 \%$ \\
\hline & $100,5 \%$ & $102,1 \%$ & & $98,8 \%$ & & $99,9 \%$ & \\
\hline Inovação de produto e/ou IO & $104,7 \%$ & $103,8 \%$ & & $103,4 \%$ & & $102,0 \%$ & \\
\hline \multirow{2}{*}{ Inovação de processo e/ou IO } & 132,57 & 46,69 & $35,2 \%$ & 77,98 & $58,8 \%$ & 181,57 & $137,0 \%$ \\
\hline & $102,8 \%$ & $102,1 \%$ & & $102,2 \%$ & & $101,1 \%$ & \\
\hline \multirow{2}{*}{ Inovação de produto, processo e/ou IO } & 167,19 & 52,66 & $31,5 \%$ & 80,65 & $48,2 \%$ & 212,34 & $127,0 \%$ \\
\hline & $129,6 \%$ & $115,2 \%$ & & $105,8 \%$ & & $118,2 \%$ & \\
\hline
\end{tabular}

Fonte: IBGE, Diretoria de Pesquisas, Coordenação de Indústria, Pesquisa Industrial de Inovação 2011.

De acordo com a Tabela 2, a PT é mais evidente nas empresas que realizaram mais de um tipo de inovação, com destaque para as empresas que realizaram “inovação de produto e processo” e “inovação de produto, processo e/ou IO". As empresas de grande porte que realizaram "inovação de produto e processo" e que realizaram “inovação de produto, processo e/ou IO” tiveram os valores da PT superiores aos dos demais grupos de empresas, inclusive ao grande grupo das empresas inovadoras.

As empresas que realizaram somente um tipo de inovação tiveram baixa PT se comparadas com as empresas que realizaram mais de um tipo de inovação. Portanto, pode-se identificar que o grupo de empresas que realizaram "inovação de produto e/ou processo" e o grupo de empresas que realizaram “inovação de produto, processo e/ou IO” foram os que tiveram maiores valores de PT, principalmente as empresas de grande porte. A Tabela 3 apresenta a RLV e os “Gastos com Atividades Inovativas”.

Tabela 3: Receita Líquida de Vendas e o Total dos Gastos com atividades inovativas por grupo de empresas e por porte

\begin{tabular}{|c|c|c|c|c|c|c|c|c|c|c|c|c|c|c|c|}
\hline \multirow[b]{3}{*}{ Grupos } & \multicolumn{15}{|c|}{ Período 2009-2011 } \\
\hline & \multicolumn{3}{|c|}{ Total } & \multicolumn{4}{|c|}{ De 10 a 49 empregados } & \multicolumn{4}{|c|}{ De 50 a 249 empregados } & \multicolumn{4}{|c|}{250 ou mais empregados } \\
\hline & \begin{tabular}{|c|} 
Receita líquida \\
de vendas \\
$(1000 \mathrm{R} \$)$ \\
$(1)$
\end{tabular} & \begin{tabular}{|c|} 
Dispêndios \\
realizados nas \\
atividades \\
inovativas \\
$(1000 \mathrm{R} \$)$ \\
\end{tabular} & $\%$ & $\begin{array}{c}\text { Receita líquida } \\
\text { de vendas } \\
(1000 \mathrm{R} \$) \\
\text { (1) }\end{array}$ & $\%$ & $\begin{array}{l}\text { Dispêndios } \\
\text { realizados } \\
\text { nas } \\
\text { atividades } \\
\text { inovativas }\end{array}$ & $\%$ & $\begin{array}{c}\text { Receita líquida } \\
\text { de vendas } \\
(1000 \mathrm{R} \$) \\
\text { (1) }\end{array}$ & $\%$ & \begin{tabular}{|c|} 
Dispêndios \\
realizados nas \\
atividades \\
inovativas
\end{tabular} & $\%$ & $\begin{array}{c}\text { Receita líquida } \\
\text { de vendas } \\
(1000 \mathrm{R} \$) \\
(1)\end{array}$ & $\%$ & \begin{tabular}{|c|} 
Dispêndios \\
realizados nas \\
atividades \\
inovativas \\
\end{tabular} & $\%$ \\
\hline \multirow{2}{*}{ Inovadoras } & 2447631087 & 64863726 & $2,7 \%$ & 179405610 & $7,3 \%$ & 7988612 & $4,5 \%$ & 346578104 & $14,2 \%$ & 9740596 & $2,8 \%$ & 1921647373 & $78,5 \%$ & 47134518 & $2,5 \%$ \\
\hline & $100,0 \%$ & $100,0 \%$ & & $100,0 \%$ & & & & $100,0 \%$ & & & & $100,0 \%$ & & & \\
\hline \multirow{2}{*}{$\begin{array}{l}\text { Somente inovação } \\
\text { de produto }\end{array}$} & 15665495 & 136585 & $0,9 \%$ & 0 & $0,0 \%$ & - & $0 \%$ & 2953686 & $18,9 \%$ & 76222 & $2,6 \%$ & 10974910 & $70,1 \%$ & 42443 & $0,4 \%$ \\
\hline & $0,6 \%$ & $0,2 \%$ & & $0,0 \%$ & & $0,0 \%$ & & $0,9 \%$ & & $0,8 \%$ & & $0,6 \%$ & & $0,1 \%$ & \\
\hline \multirow{2}{*}{$\begin{array}{l}\text { Somente inovação } \\
\text { de processo }\end{array}$} & 26805378 & 1673489 & $6,2 \%$ & 5324640 & $19,9 \%$ & 344519 & $6,5 \%$ & 11295031 & $42,1 \%$ & 1189167 & $10,5 \%$ & 10185707 & $38,0 \%$ & 139802 & $1,4 \%$ \\
\hline & $1,1 \%$ & $2,6 \%$ & & $3,0 \%$ & & $4,3 \%$ & & $3,3 \%$ & & $12,2 \%$ & & $0,5 \%$ & & $0,3 \%$ & \\
\hline \multirow{2}{*}{ Somente IO } & 282560543 & - & $0,0 \%$ & 39106086 & $13,8 \%$ & - & $0,0 \%$ & 88536288 & $31,3 \%$ & - & $0,0 \%$ & 154918169 & $54,8 \%$ & - & $0,0 \%$ \\
\hline & $11,5 \%$ & $0,0 \%$ & & $21,8 \%$ & & $0,0 \%$ & & $25,5 \%$ & & $0,0 \%$ & & $8,1 \%$ & & $0,0 \%$ & \\
\hline \multirow{2}{*}{$\begin{array}{l}\text { Somente inovação } \\
\text { em marketing }\end{array}$} & 40994331 & - & $0,0 \%$ & 16539529 & $40,3 \%$ & - & $0,0 \%$ & 9031466 & $22,0 \%$ & - & $0,0 \%$ & 15423335 & $37,6 \%$ & - & $0,0 \%$ \\
\hline & $1,7 \%$ & $0,0 \%$ & & $9,2 \%$ & & $0,0 \%$ & & $2,6 \%$ & & $0,0 \%$ & & $0,8 \%$ & & $0,0 \%$ & \\
\hline \multirow{2}{*}{ IT } & 1927090291 & 64863726 & $3,4 \%$ & 90935047 & $4,7 \%$ & 7988612 & $8,8 \%$ & 192517829 & $10,0 \%$ & 9740596 & $5,1 \%$ & 1643637415 & $85,3 \%$ & 47134518 & $2,9 \%$ \\
\hline & $78,7 \%$ & $100,0 \%$ & & $50,7 \%$ & & $100,0 \%$ & & $55,5 \%$ & & $100,0 \%$ & & $85,5 \%$ & & $100,0 \%$ & \\
\hline \multirow{2}{*}{ IO e/ou marketing } & 2316986845 & 61640415 & $2,7 \%$ & 166163812 & $7,2 \%$ & 7561431 & $4,6 \%$ & 317985017 & $13,7 \%$ & 8322765 & $2,6 \%$ & 1832838016 & $79,1 \%$ & 45756219 & $2,5 \%$ \\
\hline & $94,7 \%$ & $95,0 \%$ & & $92,6 \%$ & & $94,7 \%$ & & $91,7 \%$ & & $85,4 \%$ & & $95,4 \%$ & & $97,1 \%$ & \\
\hline \multirow{2}{*}{$\begin{array}{l}\text { Inovação de produto } \\
\text { e/ou IO }\end{array}$} & 2348441385 & 62722468 & $2,7 \%$ & 149227175 & $6,4 \%$ & 7417445 & $5,0 \%$ & 318498525 & $13,6 \%$ & 8478880 & $2,7 \%$ & 1880715684 & $80,1 \%$ & 46826143 & $2,5 \%$ \\
\hline & $95,9 \%$ & $96,7 \%$ & & $83,2 \%$ & & $92,9 \%$ & & $91,9 \%$ & & $87,0 \%$ & & $97,9 \%$ & & $99,3 \%$ & \\
\hline \multirow{2}{*}{$\begin{array}{l}\text { Inovação de } \\
\text { processo e/ou IO }\end{array}$} & 2357879114 & 64544518 & $2,7 \%$ & 155256350 & $6,6 \%$ & 7950499 & $5,1 \%$ & 329200447 & $14,0 \%$ & 9646877 & $2,9 \%$ & 1873422318 & $79,5 \%$ & 46947142 & $2,5 \%$ \\
\hline & $96,3 \%$ & $99,5 \%$ & & $86,5 \%$ & & $99,5 \%$ & & $95,0 \%$ & & $99,0 \%$ & & $97,5 \%$ & & $99,6 \%$ & \\
\hline \multirow{2}{*}{$\begin{array}{l}\text { Inovação de } \\
\text { produto, processo } \\
\text { e/ou IO }\end{array}$} & 1746296698 & 57824931 & $3,3 \%$ & 73831615 & $4,2 \%$ & 7081246 & $9,6 \%$ & 157965402 & $9,0 \%$ & 8041623 & $5,1 \%$ & 1514499680 & $86,7 \%$ & 42702061 & $2,8 \%$ \\
\hline & $71,3 \%$ & $89,1 \%$ & & $41,2 \%$ & & $88,6 \%$ & & $45,6 \%$ & & $82,6 \%$ & & $78,8 \%$ & & $90,6 \%$ & \\
\hline
\end{tabular}

Fonte: IBGE, Diretoria de Pesquisas, Coordenação de Indústria, Pesquisa Industrial de Inovação 2008 e 2011. (1) Receita líquida de vendas de produtos e serviços, estimada a partir dos dados da amostra da Pesquisa Industrial Anual - Empresa 2011 e da Pesquisa Anual de Serviços 2011.

Percebe-se que os grupos de empresas que realizaram mais de um tipo de inovação somam as maiores RLV, principalmente os grupos de empresas que realizaram IO simultaneamente com outro tipo de inovação. Destaca-se que as empresas que realizaram Inovação de Produto e Processo tiveram RLV inferiores ao dos grupos que realizaram IO concomitantemente com outros tipos de inovação. A Tabela 3 mostra que, ao compararmos percentualmente os dispêndios nas atividades inovativas das empresas de pequeno porte, que realizaram mais de um tipo de inovação, com a RLV, percebe-se que são superiores aos das empresas dos mesmos grupos mas que são de médio e grande portes. 
Portanto, esses dispêndios são percentualmente superiores nas empresas de pequeno porte, porém inferiores em unidades monetárias se comparados com o das empresas de grande porte.

\section{Análise dos resultados: estatística descritiva}

A realização do estudo econométrico, que utilizou a base de dados da edição da PINTEC de 2011, teve como objetivo verificar se a IO é capaz de influenciar positivamente o desempenho (financeiro e produtivo) da indústria.

Foi realizada a análise de dados de Corte Transversal (cross-section) por se tratar de dados da PINTEC de 2011, portanto, tomados em determinado ponto no tempo. Os dados de corte transversal são dados em que uma ou mais variáveis foram coletadas no mesmo ponto do tempo (GUJARATI, 2006). Os dados de corte transversal são amplamente usados em economia e em outras ciências sociais. Em economia esta análise está ligada com a microeconomia aplicada, especificamente, entre outros, com a organização industrial (WOOLDRIDGE, 2010). Dado seu caráter estacionário, os dados em corte transversal têm seus próprios problemas, especificamente o da heterogeneidade (GUJARATI, 2006).

Os dados apresentados a seguir foram obtidos mediante o ingresso autorizado à sala de acesso a dados restritos do IBGE. Os resultados, análises e interpretações apresentados são de responsabilidade única do autor, não representando a visão oficial do IBGE, nem se constituindo estatística oficial. A Tabela 4 apresenta a média e o desvio padrão dos grupos de empresas inovadoras por variável selecionada.

Tabela 4: Variáveis Contínuas Selecionadas: Média e Desvio Padrão por grupo de empresas inovadoras

\begin{tabular}{|c|c|c|c|c|c|c|c|c|c|c|c|c|c|c|}
\hline \multirow{2}{*}{$\begin{array}{c}\text { Variáveis } \\
\text { Grupos }\end{array}$} & \multicolumn{2}{|c|}{ PO } & \multicolumn{2}{|r|}{ VTI } & \multicolumn{2}{|c|}{ PT } & \multicolumn{2}{|c|}{ RLV } & \multicolumn{2}{|r|}{ GAI } & \multicolumn{2}{|c|}{ GPD } & \multicolumn{2}{|c|}{ COEFEXP } \\
\hline & Obs. & $\begin{array}{c}\text { Média } \\
\text { (Desv p.) }\end{array}$ & Obs. & $\begin{array}{c}\text { Média } \\
\text { (Desv p.) }\end{array}$ & Obs. & $\begin{array}{l}\text { Média } \\
\text { (Desv } \\
\text { p.) }\end{array}$ & Obs. & $\begin{array}{c}\text { Média } \\
\text { (Desv p.) }\end{array}$ & Obs. & $\begin{array}{c}\text { Média } \\
\text { (Desv p.) }\end{array}$ & Obs. & $\begin{array}{c}\text { Média } \\
\text { (Desv p.) }\end{array}$ & Obs. & $\begin{array}{c}\text { Média } \\
\text { (Desv p.) }\end{array}$ \\
\hline TOTAL & 12398 & $\begin{array}{c}346.37 \\
(1444.22)\end{array}$ & 12398 & $\begin{array}{c}51985.55 \\
(1107614)\end{array}$ & 12127 & $\begin{array}{c}82.91 \\
(231.17)\end{array}$ & 12398 & $\begin{array}{l}129057.70 \\
(1798586)\end{array}$ & 12398 & $\begin{array}{c}2984.189 \\
(46150.17)\end{array}$ & 12398 & $\begin{array}{c}1180.329 \\
(29448.92)\end{array}$ & 12398 & $\begin{array}{c}8.123 \\
(27.3187)\end{array}$ \\
\hline Inovadoras & 10052 & $\begin{array}{c}381.15 \\
(1571.19)\end{array}$ & 10052 & $\begin{array}{c}60607.3 \\
(1229475)\end{array}$ & 9875 & $\begin{array}{c}86.65 \\
(248.69)\end{array}$ & 10052 & $\begin{array}{l}149502.30 \\
(1993805)\end{array}$ & 10052 & $\begin{array}{c}3679.658 \\
(51228.95)\end{array}$ & 10052 & $\begin{array}{c}1455.79 \\
(32699.53)\end{array}$ & 10052 & $\begin{array}{c}9.969 \\
(29.95883)\end{array}$ \\
\hline Somente inovação de produto & 731 & $\begin{array}{c}398.17 \\
(889.22)\end{array}$ & 731 & $\begin{array}{c}67612.35 \\
(267901.8)\end{array}$ & 727 & $\begin{array}{c}103.07 \\
(111.91)\end{array}$ & 731 & $\begin{array}{l}185585.40 \\
(891490.9)\end{array}$ & 731 & $\begin{array}{c}2879.332 \\
(20759.45)\end{array}$ & 731 & $\begin{array}{c}1052.73 \\
(4582.633)\end{array}$ & 731 & $\begin{array}{c}25.718 \\
(43.73798)\end{array}$ \\
\hline Somente inovação de processo & 2333 & $\begin{array}{c}257.89 \\
(898.97)\end{array}$ & 2333 & $\begin{array}{c}23213.73 \\
(96767.51)\end{array}$ & 2296 & $\begin{array}{c}74.21 \\
(93.45)\end{array}$ & 2333 & $\begin{array}{c}59988.08 \\
(245020.7)\end{array}$ & 2333 & $\begin{array}{c}1981.543 \\
(14141.92)\end{array}$ & 2333 & $\begin{array}{c}234.6535 \\
(2676.368)\end{array}$ & 2333 & $\begin{array}{c}.25718 \\
(5.065848)\end{array}$ \\
\hline Somente IO & 8495 & $\begin{array}{c}407.50 \\
(1678.56)\end{array}$ & 8495 & $\begin{array}{c}66448.35 \\
(1335239)\end{array}$ & 8340 & $\begin{array}{c}88.52 \\
(257.48)\end{array}$ & 8495 & $\begin{array}{l}163870.30 \\
(2161243)\end{array}$ & 8495 & $\begin{array}{c}4101.408 \\
(55565.22)\end{array}$ & 8495 & $\begin{array}{c}1637.832 \\
(35489.02)\end{array}$ & 8495 & $\begin{array}{c}10.38376 \\
(30.50503)\end{array}$ \\
\hline Somente inovação em marketing & 5947 & $\begin{array}{c}419.06 \\
(1860.85)\end{array}$ & 5947 & $\begin{array}{c}76543.83 \\
(1592492)\end{array}$ & 5845 & $\begin{array}{c}80.83 \\
(124.18)\end{array}$ & 5947 & $\begin{array}{l}183460.80 \\
(2557351)\end{array}$ & 5947 & $\begin{array}{c}4431.728 \\
(53842.38)\end{array}$ & 5947 & $\begin{array}{c}2176.173 \\
(42412.58)\end{array}$ & 5947 & $\begin{array}{c}12.1927 \\
(32.72059)\end{array}$ \\
\hline IT & 3064 & $\begin{array}{c}291.35 \\
(898.50)\end{array}$ & 3064 & $\begin{array}{c}33806.22 \\
(156820.2)\end{array}$ & 3023 & $\begin{array}{c}81.15 \\
(98.96)\end{array}$ & 3064 & $\begin{array}{c}89952.71 \\
(487839.1)\end{array}$ & 3064 & $\begin{array}{c}2195.735 \\
(15972.46)\end{array}$ & 3064 & $\begin{array}{c}429.8277 \\
(3252.708)\end{array}$ & 3064 & $\begin{array}{c}6.331593 \\
(24.35701)\end{array}$ \\
\hline IO e/ou marketing & 9420 & $\begin{array}{c}390.29 \\
(1617.26)\end{array}$ & 9420 & $\begin{array}{c}62664.71 \\
(1269792)\end{array}$ & 9249 & $\begin{array}{c}86.06 \\
(245.91)\end{array}$ & 9420 & $\begin{array}{l}154402.10 \\
(2058673)\end{array}$ & 9420 & $\begin{array}{c}3822.13 \\
(52886.55)\end{array}$ & 9420 & $\begin{array}{c}1526.399 \\
(33773.89)\end{array}$ & 9420 & $\begin{array}{l}9.873673 \\
(29.8308)\end{array}$ \\
\hline Inovação de processo e/ou IO & 8934 & $\begin{array}{c}396.12 \\
(1639.45)\end{array}$ & 8934 & $\begin{array}{c}63937.26 \\
(1302098)\end{array}$ & 8776 & $\begin{array}{c}87.34 \\
(251.50)\end{array}$ & 8934 & $\begin{array}{l}157579.30 \\
(2107756)\end{array}$ & 8934 & $\begin{array}{c}3947.23 \\
(54192.86)\end{array}$ & 8934 & $\begin{array}{c}1560.877 \\
(34607.94)\end{array}$ & 8934 & $\begin{array}{c}9.873517 \\
(29.83059)\end{array}$ \\
\hline Inovação de produto, processo e/ou IO & 9116 & $\begin{array}{c}394.42 \\
(1626.63)\end{array}$ & 9116 & $\begin{array}{c}63723.44 \\
(1289502)\end{array}$ & 8957 & $\begin{array}{c}87.51 \\
(249.59)\end{array}$ & 9116 & $\begin{array}{l}156662.40 \\
(2087518)\end{array}$ & 9116 & $\begin{array}{c}3895.104 \\
(53654.44)\end{array}$ & 9116 & $\begin{array}{c}1544.869 \\
(34264.03)\end{array}$ & 9116 & $\begin{array}{l}10.08227 \\
(30.1094)\end{array}$ \\
\hline
\end{tabular}

Fonte: Elaborado pelo autor com base nos dados do IBGE (2015).

Considerando-se os dados da Tabela 4, em relação ao Pessoal Ocupado (PO), pode-se observar que as maiores médias foram dos grupos de empresas que realizaram "somente inovação em marketing", “somente IO” e "inovação em produto e/ou IO”. Em relação ao Valor da Transformação Industrial (VTI) pode-se destacar que as maiores médias foram dos grupos de empresas que realizaram "somente inovação em marketing”, “somente inovação de produto" e "somente IO”. Considerando-se as maiores médias em relação à Produtividade do Trabalho (PT), apresentam-se os grupos de empresas que realizaram "somente IO”, "somente inovação de produto" e "inovação em produto e/ou IO”. Observa-se que as maiores médias referentes à RLV foram dos grupos “somente inovação de produto”, “somente inovação em marketing” e “somente IO” respectivamente.

Em relação aos Gastos com Atividades Inovativas (GAI), as maiores médias foram dos grupos que realizaram "somente inovação em marketing”, “somente IO” e "inovação em produto e/ou IO”. Destacase neste item que as menores médias referem-se aos grupos de empresas que realizaram "somente inovação de processo”, “IT” e “somente inovação de produto”. Portanto, pode-se sugerir que as empresas 
que realizaram somente IO ou IO concomitantemente com outro tipo de inovação (produto, processo ou marketing) possuem, em média, Gastos em Atividades Inovativas superiores se comparados aos grupos de empresas que realizaram somente inovação de produto, ou somente inovação de processo, ou IT (produto e processo).

Considerando-se as médias dos grupos de empresas acerca dos Gastos com P\&D (GPD), pode-se destacar que as maiores foram dos grupos que realizaram "somente inovação em marketing", "somente IO" e "inovação em produto e/ou IO", e as menores médias foram dos grupos "somente inovação de processo", "IT” e "somente inovação de produto". Isso significa que, em média, os maiores Gastos com P\&D foram realizados por empresas que realizaram somente IO ou IO concomitantemente com outros tipos de inovação.

Analisando-se as médias do Coeficiente de Exportação (COEFEXP) dos grupos de empresas selecionados, foi possível observar que as maiores médias foram dos grupos que realizaram "somente inovação de produto", "somente IO" e "inovação de produto, processo e IO”. A tabela 5 apresenta a frequência dos grupos de empresas inovadoras selecionados por CNAE a dois dígitos.

Tabela 5: Frequência dos grupos de empresas inovadoras selecionados por CNAE a dois dígitos

\begin{tabular}{|c|c|c|c|c|c|c|c|c|c|c|c|c|}
\hline & cnae2 & Total & Inovadoras & $\begin{array}{c}\text { Somente } \\
\text { inovação } \\
\text { de produto }\end{array}$ & $\begin{array}{c}\text { Somente } \\
\text { inovação } \\
\text { de } \\
\text { processo }\end{array}$ & $\begin{array}{c}\text { Somente } \\
\text { IO }\end{array}$ & $\begin{array}{c}\text { Somente } \\
\text { inovação } \\
\text { em } \\
\text { marketing }\end{array}$ & IT & $\begin{array}{l}\text { IO e/ou de } \\
\text { marketing }\end{array}$ & $\begin{array}{l}\text { Inovação } \\
\text { de produto } \\
\text { e/ou IO }\end{array}$ & $\begin{array}{c}\text { Inovação } \\
\text { de } \\
\text { processo } \\
\text { e/ou IO }\end{array}$ & $\begin{array}{c}\text { Inovação } \\
\text { de } \\
\text { produto, } \\
\text { processo } \\
\text { e/ou IO }\end{array}$ \\
\hline 10 & Alimentos & 1459 & 1212 & 85 & 276 & 1044 & 768 & 361 & 1158 & 1063 & 1084 & 1103 \\
\hline 11 & Bebidas & 187 & 156 & 12 & 28 & 127 & 112 & 40 & 148 & 129 & 133 & 135 \\
\hline 12 & Fumo & 37 & 28 & 0 & 4 & 24 & 12 & 4 & 26 & 24 & 24 & 24 \\
\hline 13 & Têxtil & 545 & 393 & 24 & 86 & 327 & 237 & 110 & 366 & 333 & 345 & 351 \\
\hline 14 & Vestuário & 977 & 772 & 27 & 242 & 621 & 544 & 269 & 731 & 628 & 668 & 675 \\
\hline 15 & Couro & 535 & 419 & 21 & 90 & 351 & 283 & 111 & 402 & 354 & 371 & 374 \\
\hline 16 & Madeira & 429 & 280 & 10 & 59 & 239 & 134 & 69 & 266 & 242 & 251 & 254 \\
\hline 17 & Papel & 344 & 283 & 13 & 86 & 252 & 165 & 99 & 266 & 254 & 269 & 271 \\
\hline 18 & Impressão & 269 & 215 & 3 & 74 & 172 & 127 & 77 & 199 & 174 & 191 & 193 \\
\hline 19 & Petróleo & 146 & 116 & 3 & 26 & 103 & 30 & 29 & 108 & 105 & 106 & 108 \\
\hline 20 & Químico & 649 & 555 & 74 & 78 & 478 & 309 & 152 & 518 & 495 & 489 & 506 \\
\hline 21 & Farmaco & 184 & 155 & 27 & 31 & 127 & 99 & 58 & 138 & 135 & 138 & 146 \\
\hline 22 & Borracha & 825 & 672 & 46 & 151 & 564 & 391 & 197 & 623 & 578 & 597 & 611 \\
\hline 23 & Minerais & 743 & 577 & 29 & 143 & 481 & 310 & 172 & 535 & 491 & 512 & 522 \\
\hline 24 & Metalurgia & 352 & 283 & 8 & 76 & 242 & 113 & 84 & 257 & 242 & 263 & 263 \\
\hline 25 & Metal & 1037 & 840 & 41 & 252 & 712 & 399 & 293 & 776 & 724 & 757 & 769 \\
\hline 26 & Informática & 438 & 382 & 58 & 51 & 319 & 248 & 109 & 353 & 340 & 327 & 348 \\
\hline 27 & Elétrico & 467 & 397 & 37 & 63 & 338 & 266 & 100 & 373 & 344 & 350 & 356 \\
\hline 28 & Máquinas & 984 & 840 & 118 & 165 & 715 & 464 & 283 & 762 & 741 & 743 & 769 \\
\hline 29 & Veículos & 531 & 448 & 28 & 105 & 400 & 224 & 133 & 422 & 407 & 413 & 420 \\
\hline 30 & Transporte & 130 & 103 & 5 & 23 & 84 & 61 & 28 & 97 & 84 & 89 & 89 \\
\hline 31 & Móveis & 499 & 443 & 35 & 133 & 356 & 353 & 168 & 424 & 367 & 385 & 396 \\
\hline 32 & Diversos & 390 & 314 & 15 & 59 & 263 & 231 & 74 & 307 & 265 & 269 & 271 \\
\hline 33 & Manutenção & 241 & 169 & 12 & 32 & 156 & 67 & 44 & 165 & 158 & 160 & 162 \\
\hline \multicolumn{2}{|c|}{ Total } & 12398 & 10052 & 731 & 2333 & 8495 & 5947 & 3064 & 9420 & $\mathbf{8 6 7 7}$ & 8934 & 9116 \\
\hline
\end{tabular}

Fonte: Elaborado pelo autor com base nos dados do IBGE (2015).

Observa-se, na Tabela 5, a maior frequência no grupo de empresas que realizou "IO e/ou marketing” (total: 9420) e a menor no grupo de empresas que realizou "somente inovação de produto". Ainda pela Tabela 10, dos grupos que realizaram somente um tipo de inovação, destaca-se o que o que realizou "somente IO" (total: 8495). O setor de "alimentos" foi o que possuiu a maior quantidade de empresas (1459), seguida do setor de "metal” (1037) e "máquinas" (984). A tabela 6 apresenta o total, proporção e erro padrão das variáveis binárias utilizadas no estudo.

Considerando-se os dados da Tabela 6, observa-se que a proporção da variável Cooperação (COOP) foi maior no grupo de empresas que realizou somente "inovação em marketing" (44,3\%), seguido do grupo que realizou "somente IO” (44,06\%). Considerando-se a variável Capital Estrangeiro (CE), nota-se que a maior proporção entre os grupos “somente IO” (20,89\%), “inovação de processo e/ou IO” (20,81\%) e “inovação em produto e/ou IO” (20,59\%).

Analisando-se a proporção da variável Grupo (GRU), percebe-se que o grupo de empresas que realizou "somente IO" (25,46\%) destaca-se dos demais grupos, em seguida têm-se, com proporções aproximadas, os grupos “inovação de processo e/ou IO” (25,149\%) e "somente inovação em marketing” (25,145\%). A Variável Exportação (EXP) apresenta as maiores proporções nos grupos "somente inovação 
de produto" (36,42\%), “somente inovação em marketing” (33,12\%) e "inovação em produto e/ou IO" $(31,77 \%)$.

Tabela 6: Variáveis Binárias Analisadas: total e proporção por grupo de empresas inovadoras

\begin{tabular}{|c|c|c|c|c|c|c|c|c|c|c|c|c|c|c|c|}
\hline \multicolumn{2}{|l|}{ Variáveis } & \multicolumn{2}{|c|}{ COOP } & \multicolumn{2}{|c|}{ CE } & \multicolumn{2}{|c|}{ GRU } & \multicolumn{2}{|c|}{ EXP } & \multicolumn{2}{|c|}{ APOIO } & \multicolumn{2}{|c|}{ CONT } & \multicolumn{2}{|c|}{ QMO } \\
\hline & Obs. & Total & Prop. & Total & Prop. & Total & Prop. & Total & Prop. & Total & Prop. & Total & Prop. & Total & Prop. \\
\hline Total & 2266 & 948 & $41,84 \%$ & 468 & $20,65 \%$ & 565 & $24,93 \%$ & 703 & $31,02 \%$ & 1168 & $51,54 \%$ & 1912 & $84,38 \%$ & 1634 & $72,11 \%$ \\
\hline Inovadoras & 2259 & 947 & $41,92 \%$ & 467 & $20,67 \%$ & 563 & $24,92 \%$ & 701 & $31,03 \%$ & 1166 & $51,62 \%$ & 1907 & $84,42 \%$ & 1634 & $72,33 \%$ \\
\hline Somente inovação de produto & 324 & 96 & $29,62 \%$ & 67 & $20,68 \%$ & 70 & $21,60 \%$ & 118 & $36,42 \%$ & 137 & $42,28 \%$ & 266 & $82,10 \%$ & 216 & $66,67 \%$ \\
\hline Somente inovação de processo & 335 & 109 & $32,54 \%$ & 43 & $12,84 \%$ & 67 & $20,00 \%$ & 3 & $0,89 \%$ & 163 & $48,66 \%$ & 250 & $74,63 \%$ & 231 & $68,95 \%$ \\
\hline Somente IO & 1972 & 869 & $44,07 \%$ & 412 & $20,89 \%$ & 502 & $25,46 \%$ & 625 & $31,69 \%$ & 1060 & $53,75 \%$ & 1687 & $85,55 \%$ & 1440 & $73,02 \%$ \\
\hline IT & 659 & 205 & $31,11 \%$ & 110 & $16,69 \%$ & 137 & $20,79 \%$ & 121 & $18,36 \%$ & 300 & $45,52 \%$ & 516 & $78,30 \%$ & 447 & $67,83 \%$ \\
\hline IO e/ou de marketing & 2092 & 903 & $43,16 \%$ & 427 & $20,41 \%$ & 526 & $25,14 \%$ & 656 & $31,36 \%$ & 1108 & $52,96 \%$ & 1783 & $85,23 \%$ & 1526 & $72,94 \%$ \\
\hline Inovação de produto e/ou IO & 2049 & 884 & $43,14 \%$ & 422 & $20,59 \%$ & 515 & $25,13 \%$ & 651 & $31,77 \%$ & 1080 & $52,71 \%$ & 1746 & $85,21 \%$ & 1485 & $72,47 \%$ \\
\hline Inovação de processo e/ou IO & 2008 & 880 & $43,82 \%$ & 418 & $20,82 \%$ & 505 & $25,15 \%$ & 625 & $31,13 \%$ & 1076 & $53,59 \%$ & 1716 & $85,46 \%$ & 1462 & $72,81 \%$ \\
\hline Inovação de produto, processo e/ou marketing & 2085 & 895 & $42,93 \%$ & 428 & $20,53 \%$ & 518 & $24,84 \%$ & 651 & $31,22 \%$ & 1096 & $52,57 \%$ & 1775 & $85,14 \%$ & 1507 & $72,28 \%$ \\
\hline
\end{tabular}

Fonte: Elaborado pelo autor com base nos dados do IBGE (2015).

A proporção que se destaca, em relação à variável Apoio do Governo (APOIO), refere-se ao grupo de empresas que realizaram "somente inovação em marketing” (53,95\%), seguidos dos grupos "somente IO” (53,75\%) e "inovação de processo e IO” (53,59\%). Outra variável que se pode analisar em relação à proporção é se a empresa realizou P\&D de forma contínua (CONT), onde destaca-se o grupo "somente inovação em marketing” (86,24\%), seguido dos grupos “somente IO” (85,54\%) e "inovação de processo e/ou IO” (85,45\%). Outra importante variável utilizada no estudo é a Qualidade da Mão de Obra (QMO), que apresenta maior proporção no grupo de empresas que realizou "somente inovação em marketing” (73,57\%), seguido dos grupos “somente IO” (73,02\%) e "IO e/ou de marketing” (72,94\%).

\section{Análise dos resultados econométricos}

Para essa etapa do estudo empírico, inicialmente, realizou-se um teste de correlação entre os tipos de inovação e as variáveis de desempenho RLV e PT (Tabela 7). Verifica-se que a correlação entre os diferentes tipos de inovação e as variáveis de desempenho selecionadas é majoritariamente positiva e baixa na amostra de empresas analisadas.

Tabela 7: Correlação da PT e da RLV para cada tipo de inovação realizada

\begin{tabular}{ccccccccccc}
\hline & Inovadoras & $\begin{array}{c}\text { Somente } \\
\text { inovação de } \\
\text { produto }\end{array}$ & $\begin{array}{c}\text { Somente } \\
\text { inovação de } \\
\text { processo }\end{array}$ & Somente IO & $\begin{array}{c}\text { Somente } \\
\text { inovação } \\
\text { em } \\
\text { marketing }\end{array}$ & IT & $\begin{array}{c}\text { IO e/ou de } \\
\text { marketing }\end{array}$ & $\begin{array}{c}\text { Inovação de } \\
\text { produto } \\
\text { e/ou IO }\end{array}$ & $\begin{array}{c}\text { Inovação de } \\
\text { processo } \\
\text { e/ou IO } \\
\text { produto, } \\
\text { processo } \\
\text { e/ou IO }\end{array}$ & $\begin{array}{c}\text { Inovacano de } \\
\text { PT }\end{array}$ \\
\hline PT & 0.0339 & 0.022 & -0.0182 & 0.036 & -0.0087 & -0.0044 & 0.0244 & 0.0383 & 0.031 \\
RLV & 0.0233 & 0.0076 & -0.0188 & 0.0286 & 0.029 & -0.0129 & 0.025 & 0.0286 & 0.0254 & 0.0254 \\
\hline
\end{tabular}

Fonte: Elaborado pelo autor com base nos dados do IBGE (2015). Nível de significância de 5\%. No. Observações: 12127.

Ao se comparar com a experiência internacional, observa-se uma grande heterogeneidade de resultados, sintetizados no Quadro 2. Os estudos internacionais encontram grande variabilidade de resultados, com correlação entre inovação e indicadores de desempenho variando entre (0.08) e (0.75).

Para a análise da relação entre inovação e desempenho financeiro, medido pela Receita Líquida de Vendas (RLV), e para a análise da relação entre inovação e desempenho produtivo, foram realizadas no STATA, as regressões com erro-padrão robusto, pois ela permite que a estimação obtenha estimadores não enviesados.

Para Fávero et al. (2014) a regressão robusta é um método alternativo ao método dos mínimos quadrados quando existem outliers e opta-se pela sua manutenção na análise, e visam ajustar as estimações realizadas pelo método dos mínimos quadrados considerando-se as particularidades da amostra. De acordo com Fávero et al. (2014), o STATA não permite a realização de testes para a detecção de homocedasticidade se a regressão com erro padrão robusto for realizada. Com isso, os pressupostos foram testados nas regressões que não utilizaram essa correção. 
A Tabela 8 apresenta a compilação das regressões robustas dos grupos de empresas, agregados por tipo de inovação, considerando-se a RLV como variável dependente em todos os casos.

Tabela 8: Resultados das Estimações para RLV

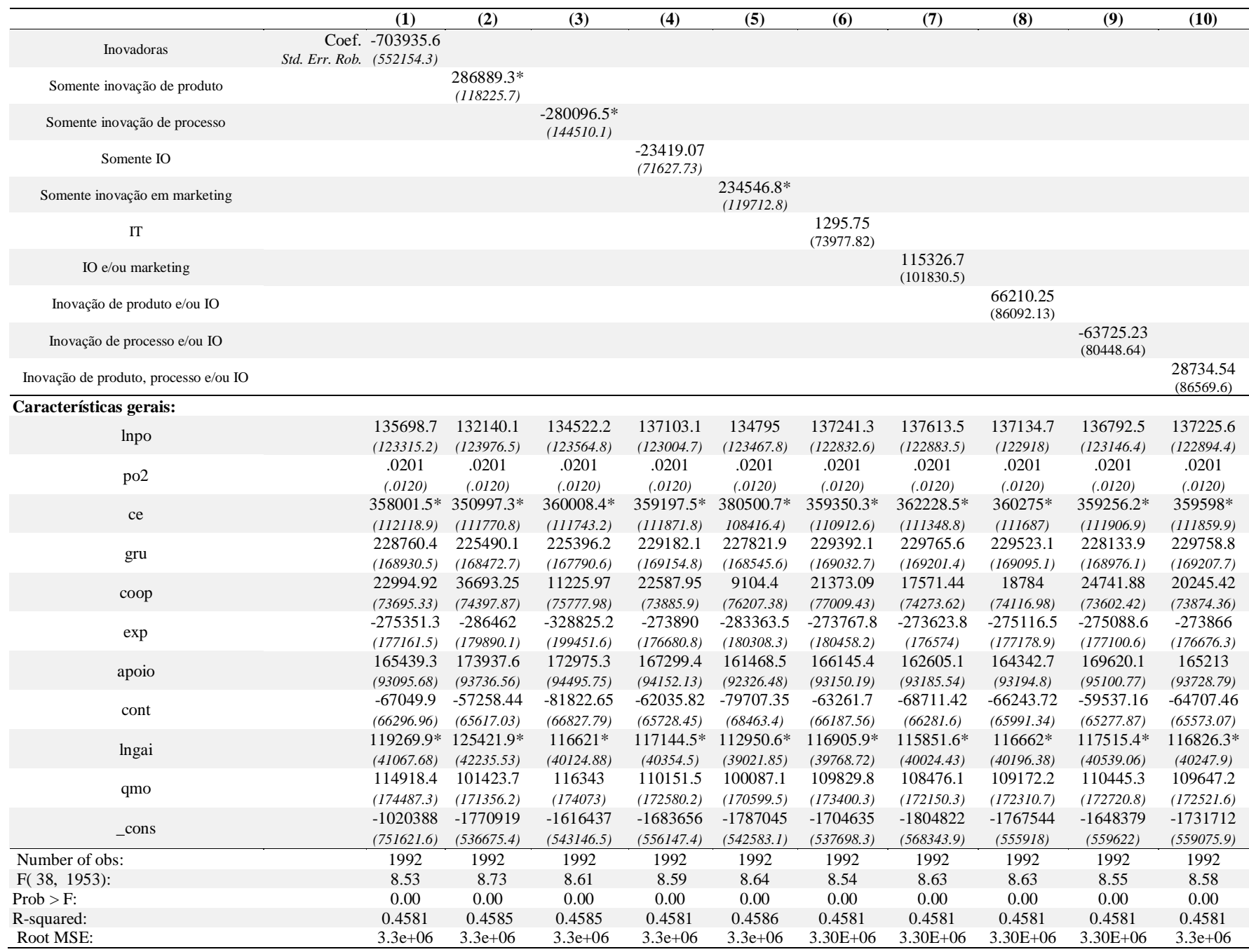

Fonte: Elaborado pelo autor com base nos dados do IBGE (2015). *Nível de significância de 5\%. Ausência de asterisco representa coeficiente não significativo. Erro Padrão Robusto estão entre parênteses. Utilizadas variáveis de controle por Região e por CNAE de dois dígitos.

De acordo com os resultados das regressões apresentados na Tabela 8, identificou-se que as empresas que realizaram "somente inovação de produto" e "somente inovação em marketing" tiveram o coeficiente associado positivo e estatisticamente significativo, demonstrando uma influência positiva desses tipos de inovação sobre o desempenho financeiro. Por outro lado, o grupo de empresas que realizaram "somente inovação de processo" apresentou coeficiente associado negativo e estatisticamente significativo, representando uma influência negativa sobre o desempenho financeiro.

Nota-se também que a variável “Capital Estrangeiro (ce)” apresenta coeficiente associado positivo e estatisticamente significativo em todos os grupos de empresas, com destaque para as empresas que realizaram "somente inovação em marketing”, por apresentar o maior coeficiente. Com isso, pode-se sugerir que o "Capital Estrangeiro" exerce influência positiva no desempenho financeiro de todos os grupos de empresas inovadoras consideradas no estudo, principalmente para as empresas que realizaram inovações em marketing.

A variável “Gastos em Atividades Inovativas (lngai)” apresenta coeficiente associado positivo e estatisticamente significativo em todos os grupos de empresas inovativas apresentadas no estudo, com destaque para as empresas do grupo que realizaram "somente inovação em produto", por apresentar o maior coeficiente entre os demais grupos. Isso sugere que os “Gastos em Atividades Inovativas” possuem 
influência positiva no desempenho financeiro. Os demais resultados não apresentaram coeficiente associado à atividade inovativa estatisticamente significativo.

Foi realizada a análise dos resíduos das regressões, com atenção a verificação dos pressupostos básicos da análise de regressão linear. Dentre os testes selecionados encontram-se os de multicolinearidade, de heterocedasticidade e de verificação do erro de especificação MQO. Nesse contexto, destaca-se que os resultados dos testes foram obtidos com auxílio do software STATA versão 12, considerando a Receita Líquida de Vendas (RLV) como variável dependente.

No que tange a verificação da existência de multicolinearidade, foi realizado o teste VIF (sigla em inglês da denominação: fator de inflação de variância). Os resultados do teste sugerem à não presença de multicolinearidade em todos os grupos, uma vez que o indicativo para existência desta seria um VIF maior que 10, conforme definido por Wooldridge (2010). Esse resultado sugere que, nas regressões apresentadas, não há ocorrência de duas ou mais variáveis independentes do modelo explicando o mesmo fenômeno.

O teste de heterocedasticidade (Breusch-Pagan/Cook-Weisberg) foi realizado em todas as regressões, sem a estimação de erro-padrão robusto. A hipótese nula é que não há heterocedasticidade, ou seja, há homocedasticidade. Observou-se que todas as regressões apresentam Prob $>\mathrm{Chi}^{2}$ de 0.0000 , ou seja, rejeita-se a hipótese nula. Nesses casos, as regressões incorrem no problema de heterocedasticidade. A ocorrência da heterocedasticidade acarretaria a estimação de parâmetros viesados na regressão, porém, as estimações realizadas com erro-padrão robusto, com a utilização do comando robust no STATA, corrigindo o problema de heterocedasticidade.

Realizou-se o teste RESET (Regression Specification Error Test) para detectar erros de especificação. A hipótese nula é de que a regressão foi corretamente especificada. Em todas as regressões realizadas a Prob>F é igual a 0.0000 ao nível de significância adotado (5\%), ou seja, rejeita-se a hipótese nula.

No que diz respeito às regressões e as respectivas estimativas dos modelos, vale ressaltar que apenas o coeficiente de "inovação de produto" foi positivo e estatisticamente significantes, demonstrando influência no desempenho produtivo. Os coeficientes das variáveis "Capital Estrangeiro (ce)", “Cooperação (coop)”, “Apoio do Governo (apoio)” e "Gastos em Atividades Inovativas (lngai)” foram positivos e estatisticamente significantes, o que implica em influência no desempenho produtivo, em todos os grupos de empresas que realizaram inovações.

A Tabela 9 apresenta os resultados das regressões robustas, considerando-se como variável dependente a PT, para todos os grupos de empresas, com a intenção de verificar a influência das variáveis explicativas sobre a variável dependente (PT) de cada grupo.

Identificou-se que, em relação ao desempenho produtivo (medido pela PT), somente "inovação de produto" apresenta coeficiente associado positivo e estatisticamente significativo, demonstrando que a realização de “inovação de produto” afeta positivamente o desempenho produtivo.

No que se refere ao conjunto de variáveis explicativas, destaca-se que:

- A variável "Pessoal Ocupado (lnpo)" apresenta coeficiente associado negativo e estatisticamente significativo em todos os grupos de empresas, com destaque para as empresas que realizaram “somente inovação de produto", por possuir o maior coeficiente negativo entre os demais;

- A variável "Capital Estrangeiro (ce)" apresenta coeficiente associado positivo e estatisticamente significativo, em todos os grupos de empresas inovadoras selecionados para a pesquisa, demonstrando uma influência positiva sobre o desempenho produtivo em todos os tipos de inovação realizadas;

- A variável “Cooperação (coop)” apresenta coeficiente associado positivo e estatisticamente significativo, representando uma influência positiva sobre o desempenho produtivo das 
empresas que realizaram "somente inovação de produto”, “somente inovação de processo", "somente inovação em marketing” e "inovação de produto e processo";

- A variável “Apoio do Governo (apoio)" apresenta coeficiente associado positivo e estatisticamente significativo, em todos os grupos de empresas inovadoras selecionados para a pesquisa, demonstrando uma influência positiva sobre o desempenho produtivo em todos os tipos de inovação realizadas;

- A variável “Gastos com Atividades Inovativas (lngai)” apresenta coeficiente associado positivo e estatisticamente significativo, em todos os grupos de empresas inovadoras selecionados para a pesquisa, demonstrando influência positiva sobre o desempenho produtivo em todos os tipos de inovação realizadas.

Tabela 9: Resultados das Estimações para PT

\begin{tabular}{|c|c|c|c|c|c|c|c|c|c|c|c|}
\hline & & (1) & (2) & (3) & (4) & (5) & (6) & (7) & (8) & (9) & (10) \\
\hline Inovadoras & $\begin{array}{l}\text { Coef. } \\
\text { Std. Err. } \\
\text { Rob. }\end{array}$ & $\begin{array}{c}-119.898 \\
(77.015)\end{array}$ & & & & & & & & & \\
\hline Somente inovação de produto & & & $\begin{array}{c}25.878^{*} \\
(7.332)\end{array}$ & & & & & & & & \\
\hline Somente inovação de processo & & & & $\begin{array}{c}1.456 \\
(12.287)\end{array}$ & & & & & & & \\
\hline Somente IO & & & & & $\begin{array}{c}-38.544 \\
(28.2442)\end{array}$ & & & & & & \\
\hline Somente inovação em marketing & & & & & & $\begin{array}{l}-19.928 \\
(10.643)\end{array}$ & & & & & \\
\hline IT & & & & & & & $\begin{array}{l}15.998 \\
(8.803)\end{array}$ & & & & \\
\hline IO e/ou marketing & & & & & & & & $\begin{array}{l}-60.244 \\
(46.648)\end{array}$ & & & \\
\hline Inovação de produto e/ou IO & & & & & & & & & $\begin{array}{l}-40.800 \\
(34.879)\end{array}$ & & \\
\hline Inovação de processo e/ou IO & & & & & & & & & & $\begin{array}{c}-43.218 \\
(32.062)\end{array}$ & \\
\hline Inovação de produto, processo e/ou IO & & & & & & & & & & & $\begin{array}{l}-47.630 \\
(41.187) \\
\end{array}$ \\
\hline \multicolumn{12}{|l|}{ Características gerais: } \\
\hline lnpo & & $\begin{array}{c}-9.409 * \\
(4.320)\end{array}$ & $\begin{array}{c}-9.6060 * \\
(4.339)\end{array}$ & $\begin{array}{c}-9.130745^{*} \\
(4.403553)\end{array}$ & $\begin{array}{c}-9.389 * \\
(4.448)\end{array}$ & $\begin{array}{c}-8.936 * \\
(4.296)\end{array}$ & $\begin{array}{c}-9.274 * \\
(4.326)\end{array}$ & $\begin{array}{c}-9.334 * \\
(4.417)\end{array}$ & $\begin{array}{c}-9.073^{*} \\
(4.285)\end{array}$ & $\begin{array}{c}-9.456^{*} \\
(4.482)\end{array}$ & $\begin{array}{c}-9.102 * \\
(42.974)\end{array}$ \\
\hline po2 & & $\begin{array}{c}1.52 \\
(1.29)\end{array}$ & $\begin{array}{c}1.53 \\
(1.28)\end{array}$ & $\begin{array}{c}1.52 \\
(1.29)\end{array}$ & $\begin{array}{c}1.53 \\
(1.29)\end{array}$ & $\begin{array}{c}1.54 \\
(1.29)\end{array}$ & $\begin{array}{c}1.53 \\
(1.29)\end{array}$ & $\begin{array}{c}1.53 \\
(1.29)\end{array}$ & $\begin{array}{c}1.53 \\
(1.29)\end{array}$ & $\begin{array}{l}1.53 \\
(1.28)\end{array}$ & $\begin{array}{l}1.53 \\
(1.29)\end{array}$ \\
\hline се & & $\begin{array}{c}101.551^{*} \\
(16.788)\end{array}$ & $\begin{array}{c}101.031^{*} \\
(16.804)\end{array}$ & $\begin{array}{c}101.785^{*} \\
(16.805)\end{array}$ & $\begin{array}{c}101.469 * \\
(16.546)\end{array}$ & $\begin{array}{c}99.994 * \\
(16.227)\end{array}$ & $\begin{array}{c}101.285^{*} \\
(16.935)\end{array}$ & $\begin{array}{c}100.306 * \\
(15.795)\end{array}$ & $\begin{array}{c}101.243^{*} \\
(16.371)\end{array}$ & $\begin{array}{c}101.697^{*} \\
(16.667)\end{array}$ & $\begin{array}{c}101.445^{*} \\
(16.491)\end{array}$ \\
\hline gru & & $\begin{array}{l}26.422 \\
(14.273)\end{array}$ & $\begin{array}{c}26.178 \\
(14.288)\end{array}$ & $\begin{array}{l}26.550 \\
(14.191)\end{array}$ & $\begin{array}{l}26.185 \\
(14.024)\end{array}$ & $\begin{array}{c}26.663 \\
(14.30035)\end{array}$ & $\begin{array}{l}26.540 \\
(14.261)\end{array}$ & $\begin{array}{l}26.334 \\
(14.091)\end{array}$ & $\begin{array}{c}26.448 \\
(14.162)\end{array}$ & $\begin{array}{l}25.677 \\
(13.734)\end{array}$ & $\begin{array}{l}25.920 \\
(13.808)\end{array}$ \\
\hline coop & & $\begin{array}{c}17.902 * \\
(9.301)\end{array}$ & $\begin{array}{c}18.999 * \\
(9.218)\end{array}$ & $\begin{array}{c}17.659 * \\
(9.065)\end{array}$ & $\begin{array}{l}19.797 \\
(10.477)\end{array}$ & $\begin{array}{c}18.639 * \\
(9.609)\end{array}$ & $\begin{array}{c}19.040^{*} \\
(8.891)\end{array}$ & $\begin{array}{l}19.532 \\
(10.384)\end{array}$ & $\begin{array}{l}19.130 \\
(10.233)\end{array}$ & $\begin{array}{l}19.970 \\
(10.596)\end{array}$ & $\begin{array}{l}19.283 \\
(10.346)\end{array}$ \\
\hline $\exp$ & & $\begin{array}{c}.896 \\
(9.937)\end{array}$ & $\begin{array}{l}.0048 \\
(9.880)\end{array}$ & $\begin{array}{l}1.4173 \\
(11.268)\end{array}$ & $\begin{array}{l}1.256 \\
(9.857)\end{array}$ & $\begin{array}{l}1.931 \\
(9.700)\end{array}$ & $\begin{array}{c}3.569 \\
(10.616)\end{array}$ & $\begin{array}{c}.954 \\
(10.004)\end{array}$ & $\begin{array}{l}1.842 \\
(9.524)\end{array}$ & $\begin{array}{c}.370 \\
(10.311)\end{array}$ & $\begin{array}{c}.968 \\
(10.024)\end{array}$ \\
\hline apoio & & $\begin{array}{c}27.444 * \\
(7.937)\end{array}$ & $\begin{array}{c}28.2667^{*} \\
(7.880)\end{array}$ & $\begin{array}{c}27.528^{*} \\
(8.070)\end{array}$ & $\begin{array}{c}29.469 * \\
(8.932)\end{array}$ & $\begin{array}{c}27.961 * \\
(8.051)\end{array}$ & $\begin{array}{c}27.608^{*} \\
(7.915)\end{array}$ & $\begin{array}{c}29.411^{*} \\
(8.962)\end{array}$ & $\begin{array}{c}28.672 * \\
(8.597)\end{array}$ & $\begin{array}{c}29.922 * \\
(9.209)\end{array}$ & $\begin{array}{c}29.103 * \\
(8.885)\end{array}$ \\
\hline cont & & $\begin{array}{l}-31.442 \\
(23.023)\end{array}$ & $\begin{array}{l}-30.265 \\
(23.071)\end{array}$ & $\begin{array}{l}-30.720 \\
(23.549)\end{array}$ & $\begin{array}{l}-28.613 \\
(21.494)\end{array}$ & $\begin{array}{l}-29.429 \\
(22.440)\end{array}$ & $\begin{array}{l}-29.422 \\
(23.555)\end{array}$ & $\begin{array}{l}-28.029 \\
(20.928)\end{array}$ & $\begin{array}{l}-29.048 \\
(21.580)\end{array}$ & $\begin{array}{l}-28.214 \\
(21.187)\end{array}$ & $\begin{array}{l}-28.607 \\
(21.195)\end{array}$ \\
\hline lngai & & $\begin{array}{c}15.958^{*} \\
(2.717)\end{array}$ & $\begin{array}{c}16.321^{*} \\
(2.792)\end{array}$ & $\begin{array}{c}15.550 * \\
(2.773)\end{array}$ & $\begin{array}{c}16.007^{*} \\
(2.875)\end{array}$ & $\begin{array}{c}15.882 * \\
(2.802)\end{array}$ & $\begin{array}{c}16.040^{*} \\
(2.754)\end{array}$ & $\begin{array}{c}16.079 * \\
(2.888)\end{array}$ & $\begin{array}{c}15.675^{*} \\
(2.779)\end{array}$ & $\begin{array}{c}15.989 * \\
(2.869)\end{array}$ & $\begin{array}{c}15.615^{*} \\
(2.757)\end{array}$ \\
\hline qmo & & $\begin{array}{l}-11.470 \\
(18.691)\end{array}$ & $\begin{array}{c}-13.089 \\
(18.623)\end{array}$ & $\begin{array}{l}-12.359 \\
(18.505)\end{array}$ & $\begin{array}{l}-11.908 \\
(18.344)\end{array}$ & $\begin{array}{l}-11.492 \\
(18.326)\end{array}$ & $\begin{array}{l}-13.166 \\
(18.389)\end{array}$ & $\begin{array}{l}-11.583 \\
(18.059)\end{array}$ & $\begin{array}{l}-11.878 \\
(18.271)\end{array}$ & $\begin{array}{r}-11.954 \\
(18.363)\end{array}$ & $\begin{array}{l}-11.910 \\
(18.279)\end{array}$ \\
\hline _cons & & $\begin{array}{l}120.352 \\
(83.171) \\
\end{array}$ & $\begin{array}{c}-2114683 \\
(34.355) \\
\end{array}$ & $\begin{array}{c}3.473 \\
(36.560) \\
\end{array}$ & $\begin{array}{l}37.291 \\
(53.130)\end{array}$ & $\begin{array}{l}10.990 \\
(36.901)\end{array}$ & $\begin{array}{l}-4.805 \\
(36.665)\end{array}$ & $\begin{array}{l}56.633 \\
(67.775)\end{array}$ & $\begin{array}{l}43.130 \\
(61.257) \\
\end{array}$ & $\begin{array}{l}41.600 \\
(56.202) \\
\end{array}$ & $\begin{array}{l}49.982 \\
(66.998)\end{array}$ \\
\hline Number of obs: & & 1992 & 1992 & 1992 & 1992 & 1992 & 1992 & 1992 & 1992 & 1992 & 1992 \\
\hline$F(38,1953):$ & & 13.40 & 13.92 & 13.46 & 13.26 & 13.31 & 13.67 & 13.36 & 13.21 & 13.18 & 13.11 \\
\hline Prob $>$ F: & & 0.0000 & 0.0000 & 0.0000 & 0.0000 & 0.0000 & 0.0000 & 0.0000 & 0.0000 & 0.0000 & 0.0000 \\
\hline R-squared: & & 0.1535 & 0.1546 & 0.1530 & 0.1565 & 0.1548 & 0.1541 & 0.1582 & 0.1562 & 0.1570 & 0.1568 \\
\hline Root MSE: & & 196.69 & 196.55 & 196.74 & 196.33 & 196.54 & 196.62 & 196.13 & 196.37 & 196.28 & 196.31 \\
\hline
\end{tabular}

Fonte: Elaborado pelo autor com base nos dados do IBGE (2015). *Nível de significância de 5\%. Ausência de asterisco representa coeficiente não significativo. Erro Padrão Robusto estão entre parênteses. Utilizadas variáveis de controle por Região e por CNAE de dois dígitos.

Também foram realizados os testes de multicolinearidade, heterocedasticidade e MQO nas regressões, considerando a Produtividade do Trabalho (PT) como variável dependente. Foi realizado o teste VIF para verificar a existência de multicolinearidade, e os resultados sugerem a não presença de multicolinearidade em todas as regressões realizadas. Cabe ressaltar que não há ocorrência de duas ou mais variáveis independentes do modelo explicando o mesmo fenômeno.

Assim como nos testes de heterocedasticidade, o teste de Breusch-Pagan/Cook-Weisberg foi realizado em todas as regressões, sem a estimação de erro-padrão robusto. A hipótese nula é que não há 
heterocedasticidade, ou seja, há homocedasticidade. Nota-se que todas as regressões apresentam Prob $>\mathrm{Chi}^{2}$ de 0.000 , ou seja, rejeita-se a hipótese nula. Nesses casos, as regressões incorrem no problema de heterocedasticidade. Por outro lado, ressalta-se que as estimações foram realizadas com erro-padrão robusto, com a utilização do comando robust no STATA, que corrige o problema de heterocedasticidade. O teste RESET (Regression Specification Error Test) foi realizado para detectar erros de especificação, considerando-se que a hipótese nula é de que a regressão foi corretamente especificada. Observa-se em todas as regressões realizadas que a Prob>F é igual a 0.000 ao nível de significância de 5\%, ou seja, rejeita-se a hipótese nula.

\section{Considerações finais}

O objetivo deste estudo foi identificar os efeitos da IO no desempenho das empresas industriais brasileiras. Realizou-se pesquisa nos principais papers internacionais acerca de estudos relacionados com a IO e seu impacto no desempenho das empresas, que tiveram seus principais resultados apresentados neste estudo.

Com base nos resultados dos estudos internacionais, pode-se considerar a importante contribuição que a IO possui para o desempenho favorável das empresas. Pode-se destacar que a relação entre IT, IO e competitividade do produto é positiva e a integração da IT com a IO é fundamental para a melhoria da competitividade dos produtos. As empresas que foram persistentes na IO foram beneficiadas com seus efeitos (positivos) no seu desempenho e o efeito combinado das IO e IT aumentou os benefícios gerados pelas empresas. As IO e a capacidade tecnológica de produtos e processos contribuem para o desempenho superior da empresa e isso mostra que as IO favorecem o desenvolvimento de capacidades de IT.

Os resultados desses estudos mostram ainda que adotar os tipos de inovação de forma combinada ao longo do tempo, faz com que a empresa desenvolva capacidades organizacionais que afetam o comportamento organizacional e o resultado das empresas. As estratégias que introduzem conjuntamente inovações produtos, processos e IO proporcionaram clara vantagem competitiva para as empresas adotantes. Outro importante aspecto das IO é que, além de prepararem um ambiente adequado para a realização de outros tipos de inovação, ela proporciona um impacto positivo no desempenho inovador.

A Receita Líquida de Vendas (RLV) do grupo de empresas que realizou “somente IO” foi superior, se comparado com os demais grupos que realizaram somente um tipo de inovação. Cabe ressaltar que a RLV foi superior na PINTEC de 2011 para esse grupo de empresas se comparado com os da PINTEC de 2008. Tratando-se das empresas que realizaram IO simultaneamente com outros tipos de inovações, destacam-se a RLV desses grupos foi superior ao do grupo que realizou IT. Pode-se sugerir que a realização de $\mathrm{IO}$, concomitantemente com outro tipo de inovação (Produto, Processo ou Marketing), alavancou a RLV das empresas do estudo.

Os resultados da Produtividade do Trabalho (PT) foram superiores nas empresas que realizaram, concomitantemente, mais de um tipo de inovação, com destaque para as empresas que realizaram IT e Inovação de Produto, Processo e IO, e as empresas que realizaram somente um tipo de inovação tiveram baixa PT se comparadas com as empresas que realizaram mais de um tipo de inovação.

As empresas que realizaram somente IO, ou IO concomitantemente com outro tipo de inovação (produto, processo ou marketing), apresentaram, em média, Gastos com Atividades Inovativas (gai) superiores aos dos grupos de empresas que realizaram somente inovação de produto, ou somente inovação de processo, ou IT (produto e processo).

Em relação ao desempenho financeiro, as empresas que realizaram "somente inovação de produto" e "somente inovação em marketing” tiveram o coeficiente associado positivo e estatisticamente significativo, demonstrando uma influência positiva sobre o desempenho financeiro. O grupo de empresas que realizaram "somente inovação de processo" apresentou coeficiente associado negativo e estatisticamente significativo, representando uma influência negativa sobre o desempenho financeiro.

O coeficiente de "inovação de produto" foi positivo e estatisticamente significativo, demonstrando influência no desempenho financeiro, bem como as variáveis “Capital Estrangeiro (ce)” e "Gastos em 
Atividades Inovativas (lngai)” tiveram coeficientes positivos e estatisticamente significativos. Pode-se então sugerir que inovação de produto possui influência positiva no desempenho financeiro. $\mathrm{O}$ "Capital Estrangeiro (ce)" e os "Gastos em Atividades Inovativas (lngai)" possuem influência positiva no desempenho financeiro em todos os grupos de empresas inovadoras consideradas no estudo. As demais variáveis consideradas como de Características Gerais não foram estatisticamente significativas. Portanto, possuir "Capital Estrangeiro” e realizar “Gastos em Atividades Inovativas” importam para as empresas inovadoras.

Em relação ao desempenho produtivo, a “inovação de produto” foi o único tipo de inovação a apresentar coeficiente associado positivo e estatisticamente significativo. Sugere-se então, que a realização de "inovação de produto" afeta positivamente o desempenho produtivo. Verifica-se, ainda, que o investimento de "Capital Estrangeiro" (mesmo que parcialmente), da "Cooperação" entre empresas, do "Apoio do Governo" para a realização de inovações e da "Qualidade da Mão de Obra”, importam para as empresas, pois eles influenciam positivamente no desempenho produtivo, em todos os grupos de empresas.

Considerando que o objetivo deste estudo foi verificar se a IO é capaz de influenciar positivamente o desempenho das indústrias de transformação situadas no Brasil, foi possível observar, com base nos resultados, que somente a IO, ou a IO realizada concomitantemente com outros tipos de inovação, não apresentaram influência significativa no desempenho financeiro (RLV) e produtivo (PT) das empresas pesquisadas.

Uma hipótese explicativa acerca dos resultados deste estudo é que o foco das empresas situadas no Brasil pode estar concentrado na realização de inovação de produto e na inovação em marketing, com a intenção de realização de resultados financeiros favoráveis, e em relação ao desempenho produtivo, elas direcionam seu foco para a inovação do produto. Apesar dos diversos estudos internacionais apontarem que a IO influencia positivamente o desempenho das empresas, os resultados obtidos com este estudo nas empresas situadas no Brasil não apontaram esta influência, possivelmente porque muitas dessas empresas não consideram este tipo de inovação relevante, como também por não conseguirem mensurar seu impacto nos resultados financeiro e produtivo, o que, com o tempo, pode-se tornar um tipo de inovação relevante, como em outros países.

Realizadas as considerações acerca da IO e seu relacionamento com a IT, pode-se indicar para estudos futuros, a avaliação no nível da empresa (considerando alguns indicadores como o grau de internacionalização da produção, exportações, características dos gestores, etc.) e no nível da indústria (considerando alguns indicadores da indústria de tererminado ramo de atividade). Pode-se realizar estudo semelhante realizando-se a análise por porte/tamanho das empresas.

Algumas limitações foram encontradas para a realização da pesquisa. Uma delas está relacionada com a base de dados utilizada, tornando os resultados representativos apenas para as empresas pesquisadas. Os resultados referem-se às indústrias de transformação, portanto, empresas de outros setores (comércio, serviços, extrativas, por exemplo) não foram pesquisadas. Outra limitação refere-se ao período de análise, que não considerou edições anteriores da PINTEC (2000, 2003 e 2005). Outros dados não foram liberados pelo IBGE e constam nas tabelas com o valor zerado, por verificação do coeficiente de variação.

\section{Referências}

ARAGON-CORREA, J. A.; GARCIA-MORALES, V. J.; CORDON-POZO, E. Leadership and organizational learning's role on innovation and performance: Lessons from Spain. Industrial Marketing Management, v. 36, n. 3, p. 349-359, 2007.

BAER, M.; FRESE, M. Innovation is not enough: climates for initiative and psychological safety, process innovations, and firm performance. Journal of Organizational Behavior, v. 24, n. 1, p. 45-68, 2003. 
BOWEN, F.; ROSTAMI, M.; STEEL, P. Timing is everything: a meta-analysis of the relationships between organizational performance and innovation. Journal of Business Research, n. 63, p. 11791185, 2010.

CALANTONE, R. J.; CAVUSGIL, S. T.; ZHAO, Y. Learning orientation, firm innovation capability, and firm performance. Industrial Marketing Management, v. 31, n. 6, p. 515-524, 2002.

CAMERON, A. C.; TRIVEDI, P. K. Microeconometrics using STATA. Texas: STATA Press, 2010.

CAMISÓN, C.; VILLAR-LÓPEZ, A. Non-technical innovation: organizational memory and learning capabilities as antecedent factors with effects on sustained competitive advantage. Industrial Marketing Management, v. 40, p. 1294-1304, 2011.

Organizational innovation as an enabler of technological innovation capabilities and firm performance. Journal of Business Research, v. 67, p. 2891-2902, 2014.

CAROLI, E.; VAN REENEN, J. Skill biased organizational change? Evidence from a panel of British and French establishments. The Quarterly Journal of Economics, v. 116, n. 4, p. 1149-1192, 2001.

DAMANPOUR, F.; SZABAT, K. A.; EVAN, W. M. The relationship between types of innovation and organizational performance. Journal of Management Studies, v. 26, n. 6, p. 587-601, 1989.

DAMANPOUR, F.; WALKER, R. M.; AVELLANEDA, C. N. Combinative effects of innovation types and organizational performance: a longitudinal study of service organizations. Journal of Management Studies, v. 46, n. 4, p. 650-675, 2009.

EVANGELISTA, R.; VEZZANI, A. The economic impact of technological and organizational innovations: a firm-level analysis. Research Policy, n. 39, p. 1253-1263, 2010.

FÁVERO, P. F.; BELFIORE, P.; TAKAMATSU, R. T.; SUZART, J. Métodos quantitativos com Stata. $1^{\circ}$ ed. Rio de Janeiro: Elsevier, 2014.

GALLEGO, J.; RUBALCABA, L.; HIPP, C. Organizational innovation in small European firms: a multidimensional approach. International Small Business Journal, v. 31, fev. 2012.

GARCIA-MORALES, V. J.; MATIAS-RECHE, F.; HURTADO-TORRES, N. Influence of transformational leadership on organizational innovation and performance depending on the level of organizational learning in the pharmaceutical sector. Journal of Organizational Change Management, v. 21, n. 2, p. 188-212, 2008.

GOMES, C. M.; KRUGLIANSKAS, I. Management of external sources of technological information and innovation performance. International Journal of Innovation Management, v. 6, n. 2, 2009.

GOPALAKRISHNAN, S. Unraveling the links between dimensions of innovation and organizational performance. The Journal of High Technology Management Research, v. 11, n. 1, p. 137-153, 2000.

GREENAN, N. Organizational change, technology, employment and skills: an empirical study of French manufacturing. Cambridge Journal of Economics, v. 27, p. 287-316, 2003.

GUAN, J.; LIU, J. Integrated innovation between technology and organization. International Journal of Innovation Management, v. 4, n. 4, 2007.

GUJARATI, D. N. Econometria básica. Rio de Janeiro: Elsevier, 2006.

GUNDAY, G.; ULUSOY, G.; KILIC, K.; ALPKAN, L. Effects of innovation types on firm performance. International Journal of Production Economics, v. 133, n. 2, p. 662-676, 2011.

HASSAN, M. U.; SHAUKAT, S.; NAWAZ, M. S.; NAZ, S. Effects of innovation types on firm performance: an empirical study on Pakistan's Manufacturing Sector. Pakistan Journal of Commerce and Social Sciences, v. 7, n. 2, p. 243-262, 2013.

HUANG, C. J.; LIU, C. J. Exploration for the relationship between innovation, IT and performance. Journal of Intellectual Capital, v. 6, n. 2, p. 237-252, 2005. 
IBGE - Instituto Brasileiro de Geografia e Estatística. Pesquisa de inovação - PINTEC 2008. Rio de Janeiro: IBGE, 2010.

IBGE - Instituto Brasileiro de Geografia e Estatística. Pesquisa de inovação - PINTEC 2011. Rio de Janeiro: IBGE, 2013.

JIMÉNEZ- JIMÉNEZ, D.; SANZ-VALLE, R. Innovation, organizational learning, and performance. Journal of Business Research, v. 64, n. 4, p. 408-417, 2011.

KESSLER, E. H. Organizational innovation: a multi-level decision-theoretic perspective. International Journal of Innovation Management, v. 8, n. 3, 2004.

LAFORET, S. Organizational innovation outcomes in SMEs: effects of age, size, and sector. Journal of World Business, v. 48, p. 490-502, 2013.

LAM, A. The Oxford handbook of innovation. Oxford, UK: Oxford University, Press, 2005.

LEWIN, K. Group decisions and social change. In: Maccoby, E., Newcomb, T., Hartley, E. (Eds.), Readings in Social Psychology. New York: Rhinehart \& Winston, 1958.

LIN, R. J.; TAN, K. H.; YONG, G. Market demand, green product innovation, and firm performance: evidence from Vietnam motorcycle industry. Journal of Cleaner Production, v. 40, p. 101-107, 2013.

MOL, M. J.; BIRKINSHAW, J. The sources of management innovation: when firms introduce new management practices. Journal of Business Research, v. 62, p.1269-1280, 2009.

NORUZY, A.; DALFARD, V. M.; AZHDARI, B.; SHIRKOUHI S. N.; REZAZADEH, A. Relations between transformational leadership, organizational learning, knowledge management, organizational innovation, and organizational performance: an empirical investigation of manufacturing firms.

International Journal Advanced Manufacture Technology, v. 64, p. 1073-1085, 2013.

OCDE. Manual de Oslo: diretrizes para coleta e interpretação de dados sobre inovação. $3^{\mathrm{a}}$ ed. Rio de Janeiro: FINEP, 2005.

ORTT, J. R.; VAN DER DUIN, P. A. The evolution of innovation management towards contextual innovation. European Journal of Innovation Management, v. 11, n. 4, p. 522-538, 2008.

PALLAS, F.; BÖCKERMANN, F.; GOETZ, O.; TECKLENBURG, K. Investigating organizational innovativeness: developing a multidimensional formative measure. International Journal of Innovation Management, v. 17, n. 4, 2013.

PIVA, M.; VIVARELLI, M. The skill bias: comparative evidence and an econometric test. International Review of Applied Economics, v. 16, n. 3, p. 347-358, 2002.

PRESTER, J.; BOZAC, M. G. Are innovative organizational concepts enough for fostering innovation? International Journal of Innovation Management, v. 16, n. 1, 2012.

SALIM, I. M.; SULAIMAN, M. Impact of organizational innovation on firm performance: evidence from Malaysian-Based ICT companies. Business and Management Review, v. 1, n. 5, 2011.

SAPPRASERT, K; CLAUSEN, T. H. Organizational innovation and its effects. Industrial and Corporate Change, v. 21, n. 5, p. 1283-1305, 2012.

SOK, P.; O'CASS, A. Achieving superior innovation-based performance outcomes in SMEs through innovation resource-capability complementarity. Industrial Marketing Management, v. 40, n. 8, p. 1285-1293, 2011.

SUBRAMANIAN, A.; NILAKANTA, S. Organizational Innovativeness: exploring the relationship between organizational determinants of innovation, types of innovations, and measures of organizational performance. International Journal Management Science, v. 24, n. 6, p. 631-647, 1996.

TOTTERDELL, P. et al. An investigation of the contentes and consequences of major organizational innovations. International Journal of Innovation Management, v. 6, n. 4, 2002. 
UZKURT, C.; KUMAR, R.; ENSARI, N. Assessing organizational readiness for innovation: an exploratory study on organizational caracteristics of innovativeness. International Journal of Innovation Management, v. 10, n. 4, 2013.

WANG, L.; YEUNG, J. H. Y.; ZHANG, M. The impact of trust and contract on innovation performance: the moderating role of environmental uncertainty. International Journal of Production Economics, v. 134, n. 1, p. 114-122, 2011.

WOOLDRIDGE, J. M. Introdução à econometria: uma abordagem moderna. São Paulo: Cengage Learning, 2010. 